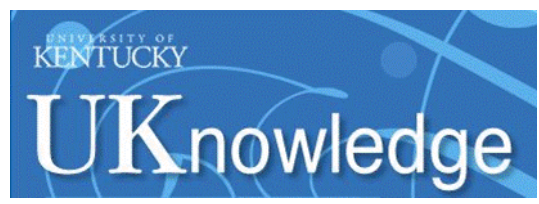

University of Kentucky

UKnowledge

7-3-2009

\title{
Enhanced disease susceptibility 1 and salicylic acid act redundantly to regulate resistance gene-mediated signaling
}

\author{
Srivathsa C. Venugopal \\ University of Kentucky \\ Rae-Dong Jeong \\ University of Kentucky, nix0125@hotmail.com \\ Mihir Kumar Mandal \\ University of Kentucky, mihir.biotech@gmail.com \\ Shifeng Zhu \\ University of Kentucky, shifeng.zhu@uky.edu
}
A. C. Chandra-Shekara
University of Kentucky

See next page for additional authors

Follow this and additional works at: https://uknowledge.uky.edu/plantpath_facpub

Part of the Plant Pathology Commons

Right click to open a feedback form in a new tab to let us know how this document benefits you.

\section{Repository Citation}

Venugopal, Srivathsa C.; Jeong, Rae-Dong; Mandal, Mihir Kumar; Zhu, Shifeng; Chandra-Shekara, A. C.; Xia, Ye; Hersh, Matthew; Stromberg, Arnold J.; Navarre, DuRoy; Kachroo, Aardra; and Kachroo, Pradeep, "Enhanced disease susceptibility 1 and salicylic acid act redundantly to regulate resistance genemediated signaling" (2009). Plant Pathology Faculty Publications. 4.

https://uknowledge.uky.edu/plantpath_facpub/4

This Article is brought to you for free and open access by the Plant Pathology at UKnowledge. It has been accepted for inclusion in Plant Pathology Faculty Publications by an authorized administrator of UKnowledge. For more information, please contact UKnowledge@lsv.uky.edu. 


\section{Enhanced disease susceptibility 1 and salicylic acid act redundantly to regulate resistance gene-mediated signaling}

Digital Object Identifier (DOI)

http://dx.doi.org/10.1371/journal.pgen.1000545

Notes/Citation Information

Published in PLoS Genetics, v. 5, no. 7, e1000545.

This is an open-access article distributed under the terms of the Creative Commons Public Domain declaration which stipulates that, once placed in the public domain, this work may be freely reproduced, distributed, transmitted, modified, built upon, or otherwise used by anyone for any lawful purpose.

\section{Authors}

Srivathsa C. Venugopal, Rae-Dong Jeong, Mihir Kumar Mandal, Shifeng Zhu, A. C. Chandra-Shekara, Ye Xia, Matthew Hersh, Arnold J. Stromberg, DuRoy Navarre, Aardra Kachroo, and Pradeep Kachroo 


\title{
Enhanced Disease Susceptibility 1 and Salicylic Acid Act Redundantly to Regulate Resistance Gene-Mediated Signaling
}

\author{
Srivathsa C. Venugopal ${ }^{1 \text { aa }}$, Rae-Dong Jeong ${ }^{1}$, Mihir K. Mandal ${ }^{1}$, Shifeng Zhu $^{1}$, A. C. Chandra-Shekara ${ }^{1 \mathrm{xb}}$, \\ Ye Xia ${ }^{1}$, Matthew Hersh ${ }^{2}$, Arnold J. Stromberg ${ }^{2}$, DuRoy Navarre ${ }^{3}$, Aardra Kachroo ${ }^{1}$, Pradeep Kachroo ${ }^{1 *}$ \\ 1 Department of Plant Pathology, University of Kentucky, Lexington, Kentucky, United States of America, 2 Department of Statistics, University of Kentucky, Lexington, \\ Kentucky, United States of America, 3 United States Department of Agriculture-Agricultural Research Service, Washington State University, Prosser, Washington, United \\ States of America
}

\begin{abstract}
Resistance (R) protein-associated pathways are well known to participate in defense against a variety of microbial pathogens. Salicylic acid (SA) and its associated proteinaceous signaling components, including enhanced disease susceptibility 1 (EDS1), non-race-specific disease resistance 1 (NDR1), phytoalexin deficient 4 (PAD4), senescence associated gene 101 (SAG101), and EDS5, have been identified as components of resistance derived from many R proteins. Here, we show that EDS1 and SA fulfill redundant functions in defense signaling mediated by R proteins, which were thought to function independent of EDS1 and/or SA. Simultaneous mutations in EDS1 and the SA-synthesizing enzyme SID2 compromised hypersensitive response and/or resistance mediated by $\mathrm{R}$ proteins that contain coiled coil domains at their $\mathrm{N}$ terminal ends. Furthermore, the expression of $R$ genes and the associated defense signaling induced in response to a reduction in the level of oleic acid were also suppressed by compromising SA biosynthesis in the eds 1 mutant background. The functional redundancy with SA was specific to EDS1. Results presented here redefine our understanding of the roles of EDS1 and SA in plant defense.
\end{abstract}

Citation: Venugopal SC, Jeong R-D, Mandal MK, Zhu S, Chandra-Shekara AC, et al. (2009) Enhanced Disease Susceptibility 1 and Salicylic Acid Act Redundantly to Regulate Resistance Gene-Mediated Signaling. PLoS Genet 5(7): e1000545. doi:10.1371/journal.pgen.1000545

Editor: Gregory P. Copenhaver, The University of North Carolina at Chapel Hill, United States of America

Received March 26, 2009; Accepted June 1, 2009; Published July 3, 2009

This is an open-access article distributed under the terms of the Creative Commons Public Domain declaration which stipulates that, once placed in the public domain, this work may be freely reproduced, distributed, transmitted, modified, built upon, or otherwise used by anyone for any lawful purpose.

Funding: This work was supported by grants from NSF (MCB\#0421914), USDA-NRI (2004-03287), and KSEF (419-RDE-004, 555-RDE-005, 622-RDE-006). The funders had no role in study design, data collection and analysis, decision to publish, or preparation of the manuscript.

Competing Interests: The authors have declared that no competing interests exist.

*E-mail: pk62@uky.edu

wa Current address: Metahelix Life Sciences Private Limited, Bangalore, India

ab Current address: Dow AgroSciences, Indianapolis, Indiana, United States of America

\section{Introduction}

Plants have evolved highly specific mechanisms to resist pathogens. One of the common ways to counter pathogen growth involves the deployment of resistant $(\mathrm{R})$ proteins, which confer protection against specific races of pathogens carrying corresponding avirulence $(A v r)$ genes [1]. Following recognition of the pathogen, one or more signal transduction pathways are induced in the host plant and these lead to the prevention of colonization by the pathogen. Induction of defense responses is often accompanied by localized cell death at the site of pathogen entry. This phenomenon, termed the hypersensitive response (HR), is one of the earliest visible manifestations of induced defense reactions and resembles programmed cell death in animals [1-6]. Concurrent with HR development, defense reactions are triggered in both local and distant parts of the plant and accompanied by a local and systemic increase in endogenous salicylic acid (SA) levels and the upregulation of a large set of defense genes, including those encoding pathogenesis-related (PR) proteins [7-9].

The SA signal transduction pathway plays a key role in plant defense signaling (see reviews in [10-12]). Arabidopsis mutants that are impaired in SA responsiveness, such as $n p r 1$ (Nonexpressor of PR; [13-15]), or are defective in pathogen-induced SA accumulation, such as eds 1 (Enhanced Disease Susceptibility 1; [16]), eds5 (Enhanced Disease Susceptibility $\underline{5}$; [17]), sid 2 (isochorishmate synthase; [18]) and pad4 (Phytoalexin Deficient 4; [19]), exhibit enhanced susceptibility to pathogen infection and show impaired $P R$ gene expression. The EDS1, EDS5, PAD4, NPR1 and SID2 proteins participate in both basal disease resistance to virulent pathogens as well as $\mathrm{R}$ protein-mediated resistance to avirulent pathogens [20]. Defense signaling mediated via a majority of $\mathrm{R}$ proteins, which contain Toll-interleukin l-like (TIR) domains at their N-terminal ends, is dependent on EDS1 [21]. Conversely, the NDRl (Non-race-specific Disease Resistance) protein is required for many $\mathrm{R}$ proteins that contain coiledcoil (CG) domains at their N-terminal ends. However, several GGnucleotide binding site (NBS)-leucine rich repeat (LRR) type of $\mathrm{R}$ proteins, including RPP8, RPP13-Nd, HRT, and RPP7, signal resistance via a pathway(s) that is independent of $\mathcal{N D R} 1[21,22-$ 24]. Strikingly, the CG-NBS-LRR gene HRT, which confers resistance to Turnip Crinkle Virus (TCV), is dependent on EDS1 [23]. Besides HRT, the only other CG domain-containing R protein that utilizes an EDS1-dependent pathway is RPW8, which confers broad-spectrum resistance to powdery mildew [25]. 


\section{Author Summary}

Salicylic acid and enhanced disease susceptibility 1 are important components of resistance gene-mediated defense signaling against diverse pathogens in a variety of plants. Present understanding of plant defense signaling pathways places salicylic acid and enhanced disease susceptibility 1 downstream of resistant protein activation. In addition, enhanced disease susceptibility 1 is primarily thought to function in the signaling initiated via Tollinterleukin 1-receptor type of resistance proteins. Here, we show that salicylic acid and enhanced disease susceptibility 1 serve redundant functions in defense signaling mediated by coiled-coil-domain containing resistance proteins that were thought to function independent of enhanced disease susceptibility 1 . Furthermore, resistance signaling induced under low oleic acid conditions also requires enhanced disease susceptibility 1 and salicylic acid in a redundant manner, but these components are required upstream of resistance gene expression. Together, these results show that the functional redundancy between salicylic acid and enhanced disease susceptibility 1 has precluded their detection as required components of many resistance protein-signaling pathways.

However, RPW8 is not a typical NBS-LRR type of R protein; it contains an N-terminal transmembrane domain in addition to the CG domain. Although several components contributing to resistance against pathogens have been identified, the molecular signaling underlying $R$ gene-mediated resistance still remains obscure. Furthermore, potential relationship(s) among different downstream components and how they relay information leading to resistance remains unknown.

The EDS1 and PAD4 proteins are structurally related to lipase/ esterase-like proteins although their lipase-like biochemical functions have not been demonstrated $[16,19]$. EDS1 interacts with PAD4 and SAG (senescence associated gene) 101 and the combined activities of these proteins are required for $\mathrm{HR}$ formation and to restrict the growth of virulent bacterial strains [26]. PAD4 and SAG101 also restrict the post-invasive growth of non-pathogenic fungi in Arabidopsis [27].

In addition to the major phytohormone-mediated defense pathways, fatty acid (FA)-derived signals have emerged as important mediators of defense signaling [28-35]. The Arabidopsis SSI2/FAB2-encoded stearoyl-acyl carrier protein-desaturase (SACPD) converts stearic acid (18:0) to oleic acid (18:1). A mutation in SSI2 results in the accumulation of 18:0 and a reduction in 18:1 levels. The mutant plants show stunting, spontaneous lesion formation, constitutive $P R$ gene expression, and enhanced resistance to bacterial and oomycete pathogens $[29,36]$. Characterization of ssi2 suppressor mutants has shown that the altered defense-related phenotypes are the result of the reduction in the levels of the unsaturated FA, 18:1 [30,31,35,3740]. The altered defense-related phenotypes in ssi2 plants can be rescued by restoring the 18:1 levels via second site mutations in genes encoding a glycerol-3-phosphate (G3P) acyltransferase [ACT1, 30], a G3P dehydrogenase [GLY1, 31], and an acyl carrier protein $[A C P 4,35]$. A mutation in act1 disrupts the acylation of G3P with 18:1 resulting in the increased accumulation of 18:1, thereby restoring wild-type (wt) phenotypes in ssi2 plants. ACT1 preferentially utilizes 18:1 conjugated to the ACP4 isoform in Arabidopsis [35]. Thus, a mutation in acp 4 produces similar phenotypes as the act 1 mutant and suppresses ssi2-mediated signaling by increasing 18:1 levels [35]. A mutation in GLY1 also restores 18:1 levels in ssi2 gly 1 plants because it disrupts the formation of G3P from dihydroxyacetone phosphate [31]. Reduced availability of G3P in turn impairs the ACT1-catalyzed reaction resulting in accumulation of $18: 1$ in ssi2 gly 1 plants. Concurrently, increasing the endogenous G3P levels via exogenous application of glycerol reduces 18:1 levels and induces ssi2like phenotypes in wt plants [31,40]. This effect of glycerol is highly specific because ssi2-associated phenotypes are not induced upon glycerol treatment of act1 (defective in the acylation of G3P with 18:1) or gli1 (defective in the phosphorylation of glycerol to G3P) mutants [40].

Recently, we showed that a reduction in 18:1 levels upregulates the expression of several $R$ genes in an SA-independent manner [37]. Furthermore, we showed that pathogen resistance induced via this mode bypasses the requirement for components that are normally required for signaling downstream of $\mathrm{R}$ protein activation. For example, resistance to TCV mediated by the $R$ gene HRT (HR to TCV), requires the recessive locus $r r t$ (regulates resistance to TCV), SA, EDS1 and PAD4 [23]. Exogenous application of SA induces the expression of HRT and overcomes the requirement for $r r t$. However, exogenous SA is unable to induce HRT or confer resistance in pad4 background [23]. Interestingly, even though a reduction in 18:1 levels also upregulates HRT expression to confer resistance to TCV, this mode of resistance is independent of PAD4, SA, EDS1 and EDS5, which are required for HRT-mediated resistance to TCV [37]. Remarkably, induction of $R$ genes in response to reduced 18:1 is conserved in plants as diverse as Arabidopsis and soybean [41]. Furthermore, this low 18:1-mediated induction of defense responses was also demonstrated in rice recently [42]. Together, these studies strengthen the conserved role of 18:1 in plant defense signaling.

Here, we show that $R$ gene expression induced in response to a reduction in 18:1 levels and the associated defense signaling can be suppressed by simultaneous mutations in EDS1 and the genes governing synthesis of SA. We also show that EDS1 and SA function redundantly in $R$ gene-mediated resistance against bacterial, viral and oomycete pathogens and that EDSl also regulates signaling mediated by $\mathrm{CG}$ domain containing $\mathrm{R}$ proteins.

\section{Results}

EDS1 and SA are essential but redundant components required for $R$ gene expression induced in response to a reduction in 18:1 levels

Signaling mediated by many $R$ genes is known to require EDS 1 and/or NDR1. Previously, we have shown that ssi2 eds1 plants continue to express $R$ genes at high levels, including those that are dependent on EDS1 for their signaling [37]. To determine if NDR1 played a role in ssi2-triggered phenotypes, we generated ssi2 $n d r 1$ plants. The double-recessive plants segregated in a Mendelian fashion and all ssi2 ndr1 plants showed ssi2-like morphology in the F2, F3 and F4 generations (Figure 1A; Table S1). Although the ssi2 $n d r 1$ plants accumulated significantly less SA/SAG (Figure 1C), compared to ssi2 plants, they showed ssi2-like $P R-1$ and $R$ gene expression (Figure 1D and 1E, Figure S1A). Exogenous glycerol application, which reduces 18:1 levels, also induced $R$ gene expression in eds 1 and $n d r 1$ plants (data not shown). Together, these results suggest that $R$ gene expression induced by low 18:1 levels does not require EDS1 or NDR1.

The SA/SAG levels in ssi2 eds1 and ssi2 ndr1 plants were significantly higher compared to those in wt plants (Figure 1C). To determine whether high SA in these genotypes was responsible for increased $R$ gene expression, we generated ssi2 eds 1 sid 2 and ssi2 
A

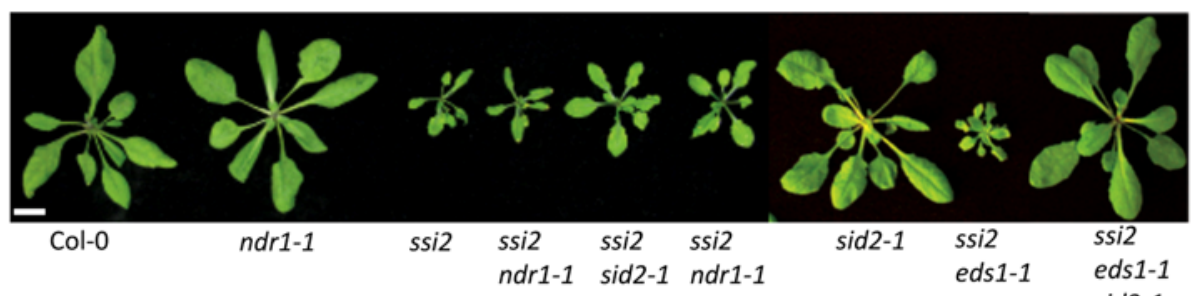

B

sid2-1

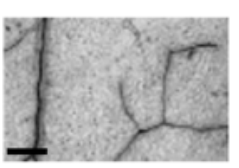

SSI2

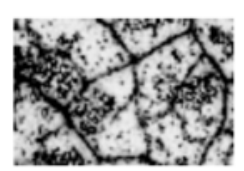

ssi2

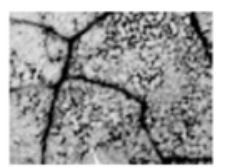

ssi2 eds1-1

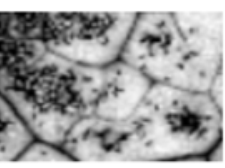

ssi2 sid2-1

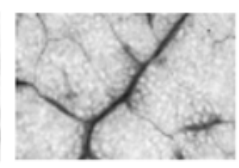

ssi2 eds1-1 sid2-1
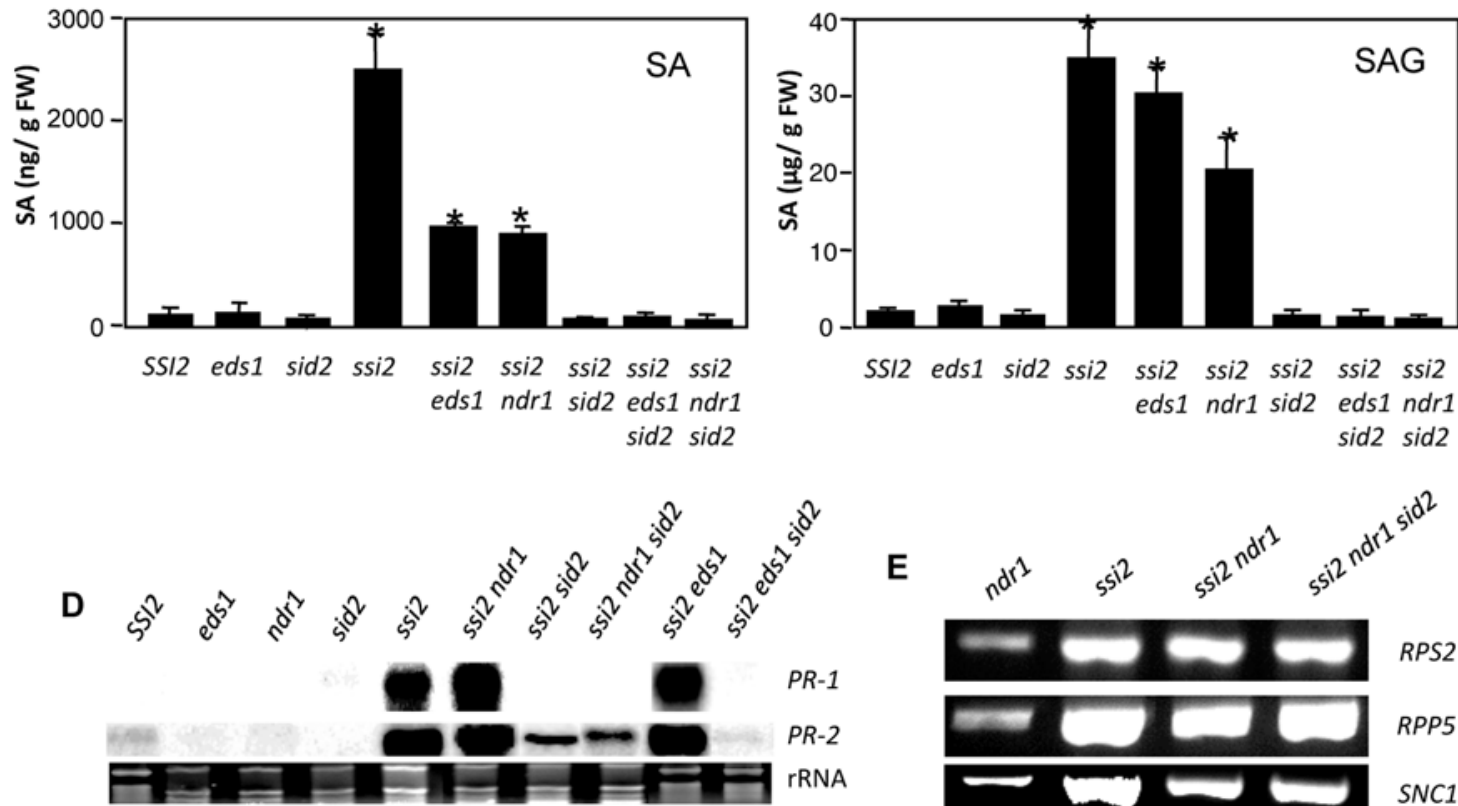

E
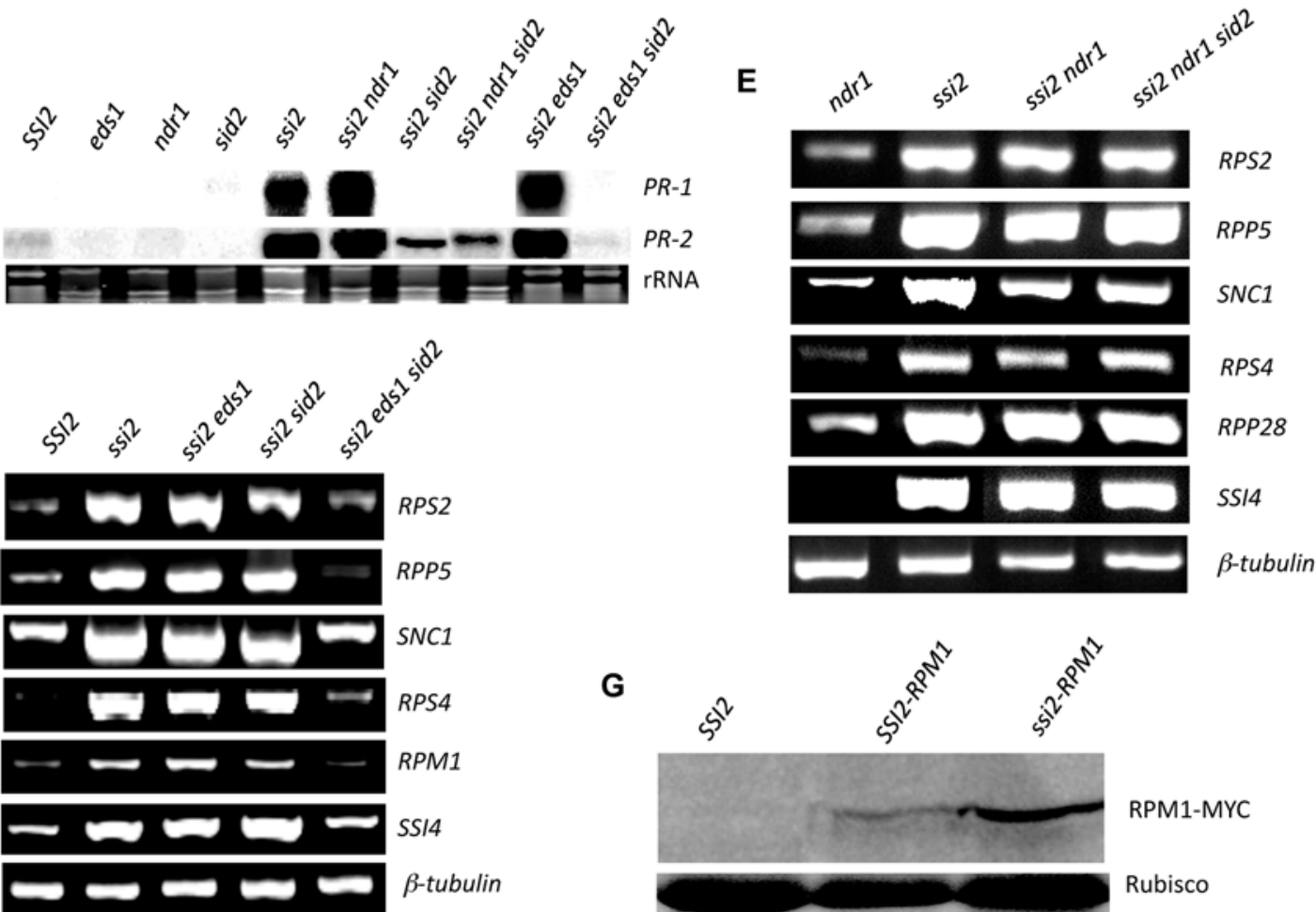

Figure 1. Morphological, molecular, and defense phenotypes of ssi2 $n d r 1-1$ sid2-1 and ssi2 eds1-1 sid2-1 plants. (A) Comparison of the morphological phenotypes displayed by 3-week-old soil-grown plants (scale, $0.5 \mathrm{~cm}$ ). (B) Microscopy of trypan blue-stained leaves from wt (SSI2, Col0 ecotype), ssi2, ssi2 eds 1-1, ssi2 sid2-1 and ssi2 eds 1-1 sid2-1 plants (scale bars, 270 microns). (C) SA and SAG levels in indicated genotypes. The error bars indicate SD. Asterisks indicate data statistically significant from wt Nö ecotype (SS/2) $(\mathrm{P}<0.05, \mathrm{n}=4)$. (D) Expression of $P R-1$ and $P R-2$ genes in indicated genotypes. Total RNA was extracted from 4-week-old plants and used for RNA gel-blot analysis. Ethidium bromide staining of rRNA was used as the loading control. The PR-1 transcript levels in EDS1 SID2 F2 plants were similar to those of wt plants (data not shown). (E) RT-PCR analysis of various $R$ genes in indicated genotypes. The level of $\beta$-tubulin was used as an internal control to normalize the amount of cDNA template. (F) RT-PCR analysis of various $R$ genes in indicated genotypes. The level of $\beta$-tubulin was used as an internal control to normalize the amount of cDNA template. The expression of $R$ genes in EDS1 SID2 F2 plants was similar to that of wt plants (data not shown). (G) Levels of Myc-tagged RPM1 protein in indicated genotypes. Levels of Rubisco were used as the loading control. doi:10.1371/journal.pgen.1000545.g001 
ndr 1 sid2 plants. Interestingly, only the ssi2 eds 1 sid2 plants showed wt-like morphology and did not develop visible or microscopic cell death (Figure 1A and 1B). In contrast, ssi2 sid2, ssi2 ndr1, ssi2 ndr1 sid 2 or ssi2 eds 1 plants exhibited ssi2-like phenotypes. PR-1 gene expression was restored to wt-like levels in the ssi2 eds 1 sid2 and ssi2 ndr1 sid2 plants, due to the sid2-derived reduction in SA levels (Figure 1D). In contrast, expression of the SA-independent PR-2 gene was restored to basal levels only in ssi2 eds1 sid2 [43], but not in ssi2 sid2 or ssi2 ndr1 sid2 plants (Figure 1D, Table S2). Most importantly, ssi2 eds1 sid2 showed basal expression of $R$ genes, unlike ssi2 $n d r 1$ sid2 plants (Figure $1 \mathrm{E}$ and $1 \mathrm{~F}$; Figure S1A, S1B; Table $\mathrm{S} 1) . R$ gene induction was further confirmed by comparing the transcript profiles of 162 NBS-LRR genes in ssi2 sid2 with that of wt plants using Affymetrix ATH1 GeneChips arrays. Twentyone NB-LRR genes were specifically expressed at 2-fold or higher levels in ssi2 sid2 plants as compared to wt (Col-0) or eds 1 plants $(\mathrm{P}<0.05)$ (Table S2). All $21 \mathrm{NB}-\mathrm{LRR}$ genes were expressed at low levels in ssi2 eds 1 sid2 plants, further confirming the results from the RT-PCR analysis. Transcriptional profiling performed using Affymetrix arrays showed that the induction of several $R$ genes (RPM1, RPS2, RPP5, RPS4) was lower than 2-fold in ssi2 or ssi2 sid2 compared to wt plants (Table S2, data not shown for ssi2). To determine if this low-level induction translated to a significant increase in R protein levels, we analyzed the levels of RPM1 in ssi2 plants. Indeed, ssi2 plants accumulated significantly higher levels of the RPM1-Myc protein (Figure 1G).

To rule out the effects of the varied ecotypes of the ssi2 sid2 eds 1 (Nössen, Col-0, Ler) plants we introduced eds1-1 (Ws-0 ecotype) and eds1-2 (Ler ecotype) alleles in ssi2 sid2 and ssi2 nahG (Nössen ecotype) backgrounds (Table S1). All combinations of ssi2 with eds1-1/eds1-2 and sid2/nahG produced similar phenotypes (data not shown). FA profiling showed that the ssi2 eds1 sid2 plants contained low 18:1 levels, similar to ssi2 plants (Table S3). We thus concluded that EDS1 and SA function downstream of 18:1 levels, but upstream of $R$ gene expression. Furthermore, ssi2 eds 1 sid 2 plants were wt-like, even though neither ssi2 eds 1 nor ssi2 sid 2 were restored for defense signaling. Therefore, EDS1 and SA likely fulfill redundant functions in defense signaling induced in response to a reduction in 18:1 levels.

To further test the redundancy for EDS1 and SA, ssi2 eds 1 sid2 plants were treated with SA or its active analog benzo(1,2,3)thiadiazole-7-carbothioic acid (BTH). Application of SA or BTH induced lesion formation on ssi2 eds 1 sid2 plants but not on wt, eds1, sid2, eds1 sid2 or EDS1 SID2 F2 plants (Figure 2A and 2B, data not shown for $e d s 1$ sid2 and EDS1 SID2). Also, application of SA or BTH induced $R$ gene expression in ssi2 eds 1 sid 2 plants (Figure 2C). Thus, application of SA restored ssi2-like phenotypes in ssi2 eds 1 sid 2 plants. Since glycerol application mimics the effects of the $s s i 2$ mutation, we generated $e d s 1$ sid 2 plants and evaluated them for their ability to induce $R$ genes in response to glycerol. Exogenous application of glycerol lowered 18:1 levels in all genotypes, but induced the expression of $R$ genes only in wt, $e d s 1$, sid2 and EDS1 SID2 F2 plants (Figure 2D, Figure S1C). Only a marginal or no increase in $R$ gene expression was observed in the eds 1 sid2 plants (Figure 2D). These results confirmed that EDS1 and SA function redundantly downstream of signaling induced by low 18:1 levels, but upstream of $R$ gene expression.

\section{EDS1 and SA function redundantly in pathogen resistance induced in response to reduction in 18:1 levels}

We next evaluated the effect of simultaneous mutations in EDS1- and SA-signaling pathways on resistance to TCV in the ssi2 background. We reported previously that resistance to TCV is dependent on the $R$ gene, HRT, and a recessive locus rrt [23].
However, the ssi2 mutation overcomes the requirement for $r r t$ in HRT-containing plants [23,37]. Furthermore, the ssi2 mutation only confers resistance to TCV when HRT is present (Figure 3A). The ssi2 mutation also overrides a requirement for EDS1 and SA and consequently ssi2 HRT eds 1 as well as ssi2 HRT sid2 plants exhibit resistance to TCV [37] (Figure 3A). Unlike HRT ssi2, HRT ssi2 eds1 or HRT ssi2 sid2 plants, the HRT ssi2 eds1 sid2 plants showed susceptibility to TCV; 85\% HRT ssi2 eds1 sid2 plants were susceptible to TCV as against $\sim 2-4 \%$ of $H R T$ ssi2 sid 2 or HRT ssi2 eds 1 plants (Figure 3A). TGV-induced expression of PR-1 is also independent of EDS1 and SA. However, TCV inoculation failed to induce $P R-1$ expression in HRT ssi2 eds 1 sid2 plants, unlike in HRT ssi2 sid2 plants (Figure 3B). These results showed that both EDS1 and SA have redundant functions in ssi2-mediated resistance to TCV in HRT plants.

\section{EDS1 and SA function redundantly in signaling mediated by $H R T$, RPS2, and RPP8 genes that encode CC-NBS-LRR proteins}

To determine the redundancy of EDS1 and SA in signaling mediated by CC-NBS-LRR R proteins, we tested the effects of mutations in EDS1- and/or SID2 on HR to TCV. Earlier, we showed that HRT-mediated HR to TCV and $P R-1$ gene expression is not affected by mutations in the EDS1 or SID2 genes [23]. Consistent with previous results, Di-17 (HRT-containing resistant ecotype), HRT sid2 and HRT eds 1 plants revealed discrete and similar-sized HR lesions on TGV-inoculated leaves (Figure 3C and 3D). In comparison, HR in HRT eds1 sid2 plants was diffused and formed larger lesions (Figure 3C and 3D). Increased lesion size in HRT eds1 sid2 plants correlated with increased accumulation of the TCV coat protein $(\mathrm{CP})$ and TCV CP transcript (Figure $3 \mathrm{E}$ and $3 \mathrm{~F}$ ). Analysis of $P R-1$ and $P R-2$ gene expression indicated that TCV-inoculated HRT eds1 sid2 plants accumulated lower levels of $P R-1$ and $P R-2$ transcripts, unlike Di-17, HRT eds1 or HRT sid2 plants (Figure 3G and $3 \mathrm{H}$ ). In contrast to $P R, H R T$ expression remained unaltered in HRT eds1 sid2 plants (Figure 3H). Together, these results suggested that EDS 1 and SA function redundantly in HRT-mediated signaling leading to $\mathrm{HR}$ formation and expression of $P R-1$. The functional redundancy with SA was specific to EDS1 and did not extend to PAD4; HRT pad4 sid2 plants showed normal replication of the virus and wt-like HR and $P R-1$ gene expression (Figure 3C-3G).

A majority of $\mathrm{CG}$-domain containing $\mathrm{R}$ proteins, including RPS2, have been reported as not requiring EDS1 for resistance signaling [21]. To determine the effect of simultaneous mutations in EDS1 and SID2 on RPS2-mediated resistance, we compared defense phenotypes produced in single or double mutant plants with that of plants lacking a functional RPS2 gene. Since different alleles of RPS2 confer varying levels of resistance to Pseudomonas syringae (containing AvrRPT2) [44], we screened and isolated an EDS1 knockout (KO) mutant (designated eds1-22) in the Col-0 background and crossed it into the sid2 background (Col-0 ecotype). Inoculation with $P$. syringae expressing AvrRPT2 induced severe chlorosis on eds1-22 sid2 leaves (Figure 4A). Similar results were obtained when $P$. syringae expressing AvrRPT2 was inoculated into eds1-1 sid2 double mutant plants (Figure S2A). Interestingly, these phenotypes were very similar to those produced on plants lacking a functional RPS2 (rsp2-101c), while eds1 and sid2 showed no or very mild symptoms, respectively (Figure 4A, Figure S2A). The appearance of symptoms correlated with bacterial growth; eds1-22 sid2 plants and the rps 2 mutant supported maximum growth of the pathogen, followed by sid2 plants (Figure $4 \mathrm{~B}$ ). Similarly, the eds1-1 sid2 double mutant plants supported more pathogen growth compared to eds1-1 or sid2 plants (data not shown). Together, these data suggest that the simultaneous loss of 
A

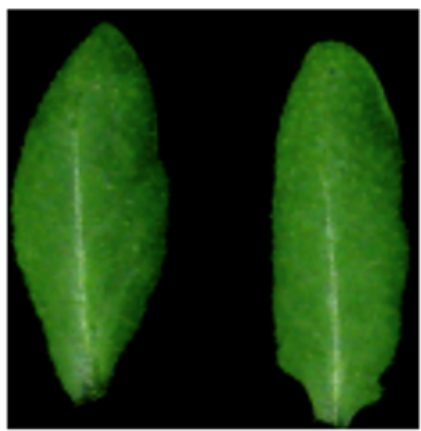

Water

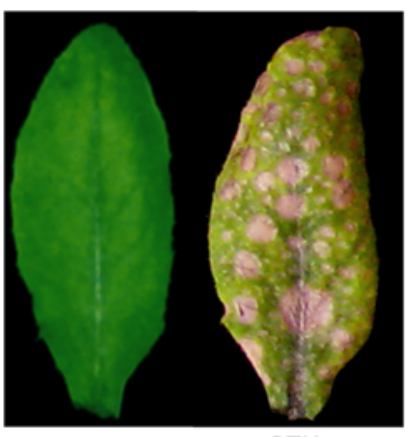

Water

BTH

B

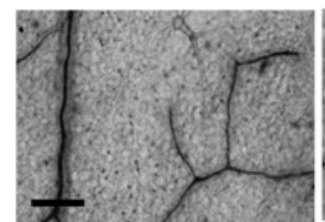

SSI2

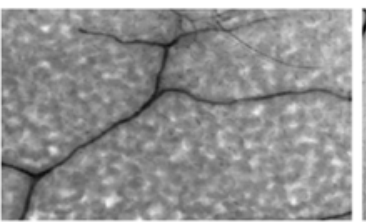

sid2-1

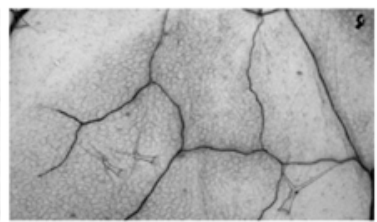

eds1-1

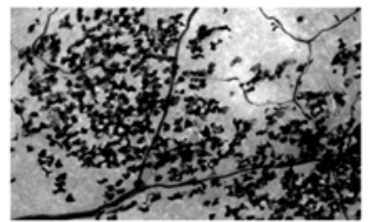

ssi2 eds1-1 sid2-1
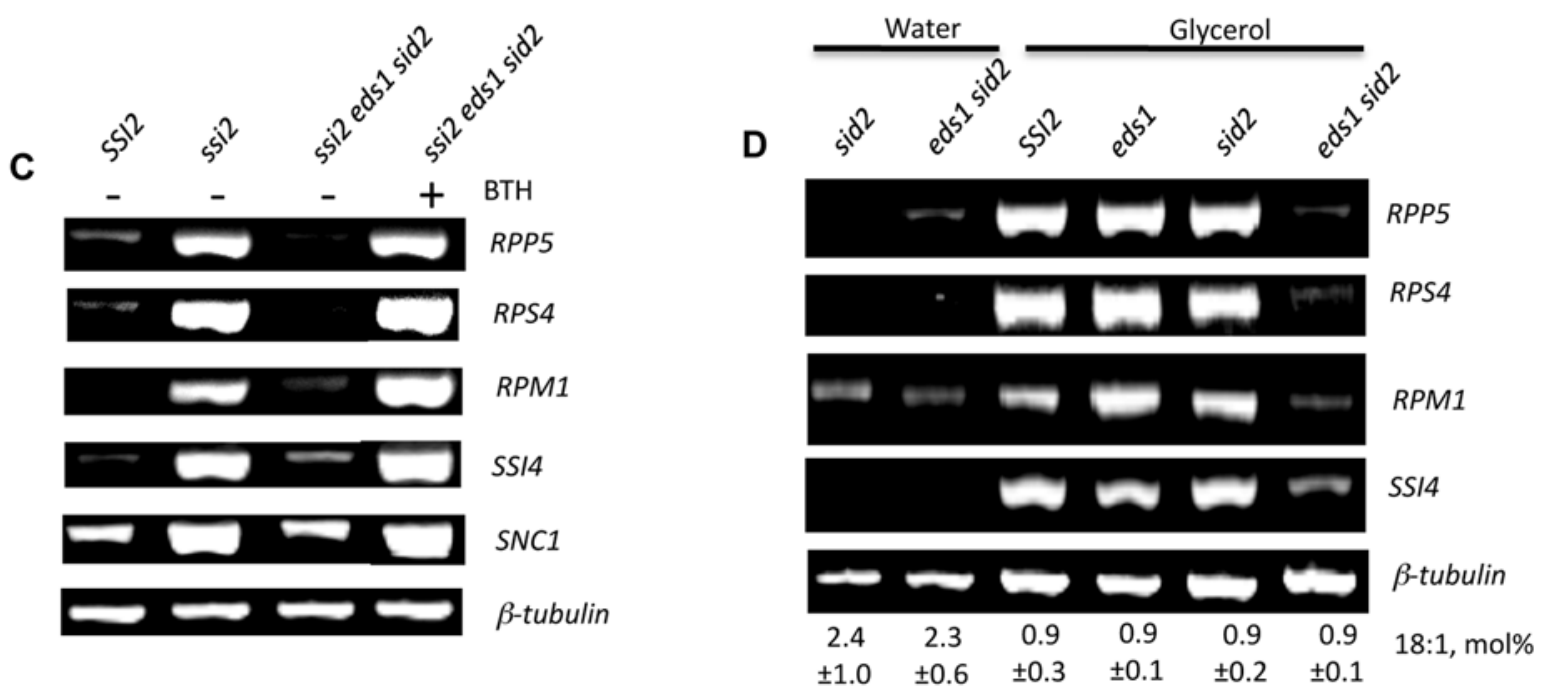

Figure 2. Restoration of $s$ si2 phenotypes in ssi2 eds1-1 sid2-1 plants and glycerol responsiveness of eds 1-1 sid2-1 plants. (A) Visual phenotypes of water- or BTH-treated wt (SSI2; Col-0 ecotype) and ssi2 eds1-1 sid2-1 plants. The plants were photographed at 2 days post treatment (dpt). (B) Microscopy of trypan blue-stained leaves from BTH-treated wt (SSI2; Col-0 ecotype), sid2, eds1-1 and ssi2 eds 1-1 sid2-1 plants. The plants were treated with BTH and stained at $2 \mathrm{dpt}$ (scale bars, 270 microns). (C) RT-PCR analysis of $R$ genes in water- or BTH-treated ssi2 eds 1-1 sid2-1 plants. Untreated wt (SSI2; Col-0 ecotype) and ssi2 plants were used as controls. The expression of $R$ genes in EDS1 SID2 F2 plants was similar to that of wt plants (data not shown). The level of $\beta$-tubulin was used as an internal control to normalize the amount of cDNA template. (D) RT-PCR analysis of various $R$ genes in water- or glycerol-treated sid2-1 and eds 1-1 sid2-1 plants. The glycerol-treated wt (SSI2; Col-0 ecotype) and eds 1-1 were included as additional controls. The expression of $R$ genes in water- or glycerol-treated EDS1 SID2 F2 plants was similar to that of water- or glycerol-treated wt plants, respectively (data not shown). The expression of $R$ genes in wt and eds1-1 plants was similar to that seen in sid2-1 or eds 1-1 sid2-1 plants. The plants were treated with water or glycerol for three days and analyzed for 18:1 levels and $R$ gene expression. The level of $\beta$-tubulin was used as an internal control to normalize the amount of CDNA template. The $18: 1$ content of each genotype is shown as mol\% \pm SD. doi:10.1371/journal.pgen.1000545.g002 


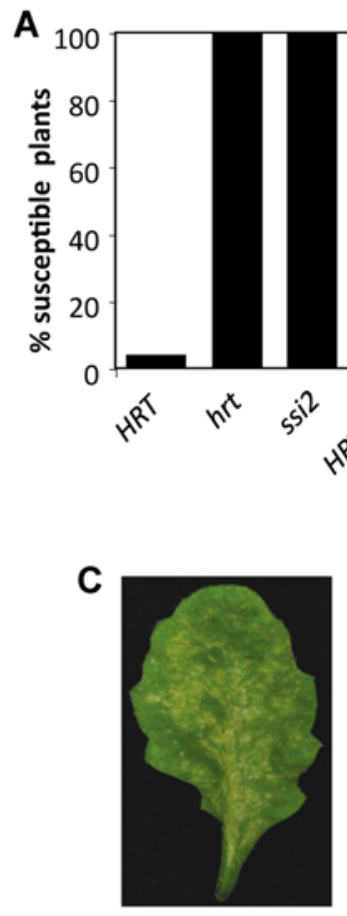

Di-17 (HRT)
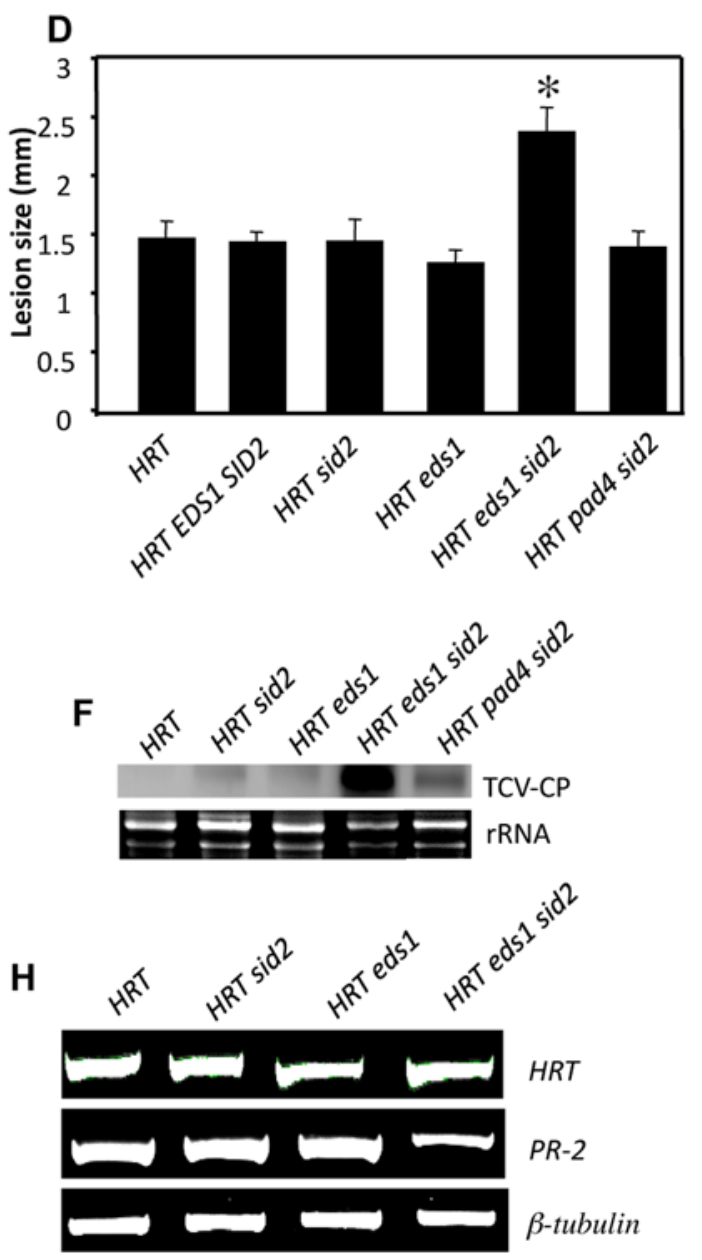
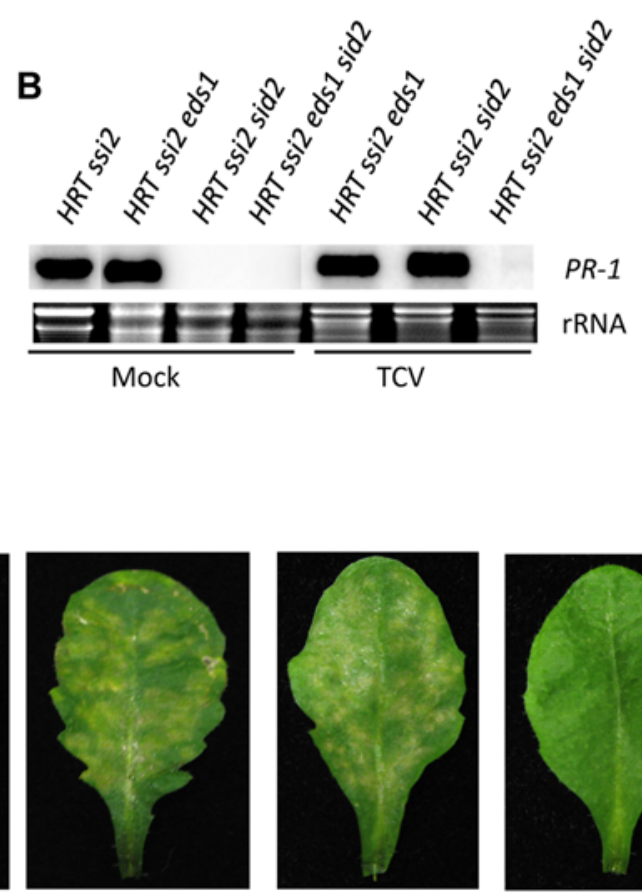

HRT pad4-1 sid2-1 Col-0 (hrt)

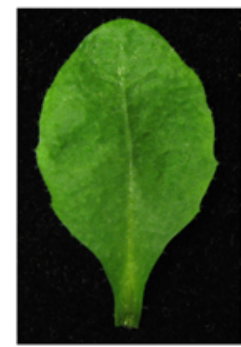

HRT eds1-1 sid2-1

E

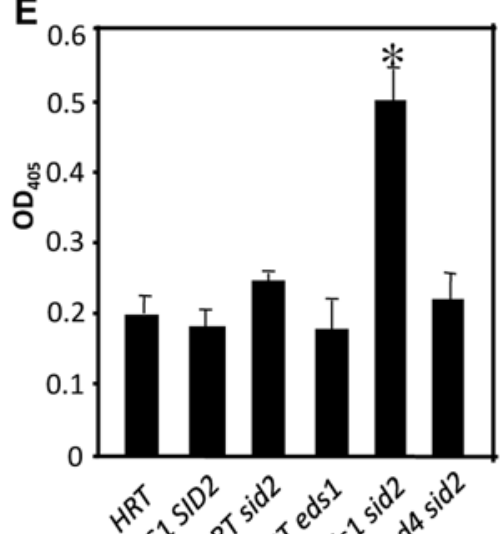

(1)

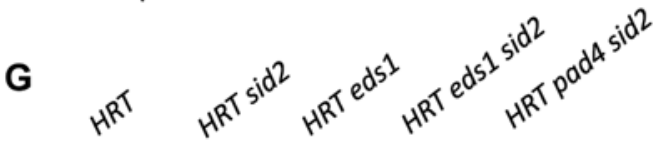

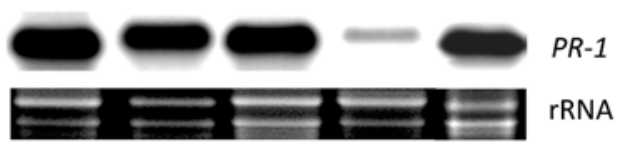


Figure 3. Interaction phenotypes of TCV with HRT ssi2 eds 1-1 sid2-1 and HRT eds 1-1 sid2-1 plants. (A) Percentage TCV susceptible plants. HRT and $h r t$ indicate resistant and susceptible ecotypes Di-17 and Col-0, respectively. Approximately $70-100$ plants were scored for each genotype threeweeks post inoculation and all susceptible plants showed crinkling phenotype and drooping of the bolt [23]. (B) Expression of $P R-1$ gene in indicated genotypes after mock- or TCV-inoculation. Total RNA was extracted from inoculated leaves at 3 dpi. Ethidium bromide staining of rRNA was used as the loading control. (C) HR formation in indicated genotypes at 3 dpi. The HR response in TCV-inoculated HRT EDS1 SID2 F2 plants was similar to that seen in TCV-inoculated Di-17, HRT sid2-1 or HRT eds1-1 plants. Plants lacking HRT (Col-0, Nö ecotypes or EDS1 SID2 F2's) did not show any HR. (D) Lesion size in indicated genotypes at $3 \mathrm{dpi}$. Lesion size was determined from $\sim 23$ individual leaves from each genotype. Statistical significance was determined using Students $t$-test. Asterisks indicate data statistically significant from those of HRT, HRT EDS1 SID2, HRT sid2-1 or HRT eds 1-1 plants $(\mathrm{P}<0.05, \mathrm{n}=23)$. The error bars indicate SD. (E) ELISA showing levels of TCV CP in the inoculated leaves of indicated genotypes at 3 dpi. Asterisks indicate data statistically significant from results for HRT (Di-17 ecotype) plants $(P<0.05, n=4)$. The error bars indicate SD. (F) Transcript levels of TCV CP in the inoculated leaves of indicated genotypes at 3 dpi. Ethidium bromide staining of rRNA was used as the loading control. (G) Expression of $P R-1$ gene in indicated genotypes. Total RNA was extracted from inoculated leaves at $3 \mathrm{dpi}$. Ethidium bromide staining of rRNA was used as the loading control. The PR-1 gene expression in TCV-inoculated HRT EDS1 SID2 F2 plants was similar to that observed in TCV-inoculated HRT, HRT eds1-1 or HRT sid2-1 plants (data not shown). (H) RT$P C R$ analysis showing HRT and $P R-2$ transcript levels in indicated genotypes. The plants were inoculated with TCV and leaf samples were harvested $24 \mathrm{~h}$ post inoculation. The level of $\beta$-tubulin was used as an internal control to normalize the amount of cDNA template. doi:10.1371/journal.pgen.1000545.g003

EDS1- and SA-dependent signals is required to mimic a phenotype produced by the loss of the cognate $R$ gene, RPS2.

To determine if the loss of both EDS1- and SA-dependent signaling impaired resistance by affecting the RPS2 protein, we analyzed R protein levels in $e d s 1-1$ and sid2 single and $e d s 1-1$ sid 2 double mutant plants. Analysis of RPS2 tagged with HA epitope at various times did not detect any significant changes in RPS2 levels in response to inoculation with $P$. syringae expressing AvrRPT2 (Figure 4C). Therefore, RPS2 levels in mutant plants were analyzed at only 12 and $24 \mathrm{~h}$ post-pathogen inoculation. The RPS2-HA levels in eds1-1, sid2 or eds1-1 sid2 plants were similar to that in wt plants (Figure 4D). These results suggested that abrogation of resistance in eds 1 sid 2 double mutants was not due to a defect in the accumulation of the $\mathrm{R}$ protein.

We next evaluated the effects of mutations in EDS1 and SID2 on RPPO-mediated resistance to Hyalopernospora arabidopsidis biotype Emco5 encoding Atro. RPPo (encodes a CG-NBS-LRR type R protein)-mediated resistance signaling was previously reported to be independent of both EDS1 and SA [21,24]. As expected, RPPo plants (ecotype Ler) inoculated with the Emco5 isolate showed localized HR and did not support growth of the pathogen (Figure 5A). Consistent with earlier reports [21,24], RPPo eds1-2 plants also did not support the growth of Emco5, although they did develop trailing necrosis (Figure $5 \mathrm{~A}$ and $5 \mathrm{~B}$ ). The presence of the $n a h G$ transgene did not alter HR formation or pathogen response in the RPPo nahG plants (Ler ecotype). In contrast, eds1-2 nah $G$ plants were affected in both HR as well as resistance; eds1-2 nahG plants not only showed extensive trailing necrosis but also supported growth and sporulation of the pathogen (Figure 5A-5C). Although RPPo EDS1 nahG and RPPo eds1-2 nah $G$ plants showed contrasting phenotypes (Figure $5 \mathrm{~A}-5 \mathrm{C}$ ), we still wanted to rule out the possibility that susceptibility of $e d s 1 \mathrm{nah} G$ plants was not due to the accumulation of catechol, which is formed upon degradation of SA by NAHG. Estimation of SA levels in Emco5 inoculated RPP 8 (Ler) plants showed marginal increase in SA and no significant increase in SAG levels compared to mock-inoculated plants (data not shown). This suggests that Emco5 inoculated nahG plants are unlikely to show a significant increase in catechol levels. In addition to this, we tested two independent lines of RPPo eds $1-2$ sid 2 (in the ssi2 background) plants and both showed increased susceptibility to Emco5 (Figure 5D). In comparison, RPPo eds1-2 or $R P P 8$ sid 2 genotypes did not support any growth or sporulation of the pathogen (Figure 5D). Taken together, these results show that EDS1 and SA have redundant functions in RPPO-mediated resistance to $H$. arabidopsidis Emco5.

\section{Exogenous SA and overexpression of EDS1 have additive effects on pathogen resistance in wild-type plants}

To determine the relation between EDS1- and SA-derived signaling, we compared $P R-1$ gene expression and resistance in plants that were either overexpressing EDS1 or were pretreated with SA. EDS1 overexpression was achieved by expressing EDS1 (At3g48090 from the Col-0 ecotype) under control of the CaMV $35 \mathrm{~S}$ promoter in Col-0 plants (Figure 6A). The 35S-EDS1 plants analyzed in the $\mathrm{T} 2$ and $\mathrm{T} 3$ generations showed wt-like morphology (data not shown), wt-like expression of the $P R-1$ gene (Figure 6A) and accumulated wt-like levels of SA/SAG (data not shown). In comparison, exogenous application of SA induced $P R-1$ and EDS1 gene expression [data not shown; 16].

Analysis of RPS4 (encodes a TIR-NBS-LRR type R protein)mediated resistance showed that exogenous application of SA enhanced resistance to $P$. syringae (expressing AvrRPS4) in wt as well as eds1-22 plants, although wt plants were more resistant to AvrRPS4 bacteria than the eds 1-22 plants (Figure 6B). Overexpression of EDS1, on the other hand, did not alter the response to AvrRPS4 bacteria. Strikingly, exogenous application of SA on 35SEDS1 plants enhanced resistance even more than in the SAtreated wt or eds1-22 plants. Together, these results suggest that EDS1- and SA-derived signaling contribute additively towards pathogen resistance.

\section{Simultaneous defects in EDS1 and SA biosynthesis do not additively lower basal defense}

We next evaluated the effect of the eds 1 sid 2 mutations on basal resistance to virulent $P$. syringae, since both EDS1 and SID2 are known to contribute to basal defense as well. The eds1-1, eds1-22, sid2 and eds1 sid2 plants all showed enhanced susceptibility to virulent bacteria as compared to the respective wt ecotypes (Figure 7A). Interestingly, unlike in the case of the avirulent bacteria, growth of virulent bacteria was similar in $e d s 1$ sid 2 double mutant plants as compared to that in eds 1 or sid 2 single mutant plants. These results suggested that loss-of-function mutations in EDS1 and SID2 do not additively reduce basal resistance to virulent $P$. syringae. Similar to the results obtained with the bacterial pathogen, the loss of both EDS1- and SA-dependent signals did not additively lower basal resistance to TCV either (Figure 7B). This further suggested that the redundant functions of EDS1 and SA might be relevant only for $R$ gene-mediated signaling.

\section{Mutations in FAD7 FAD8 and EDS5 restore altered defense signaling in ssi2 eds 1 plants}

Besides SID2, mutations in FAD7 FAD8, which catalyze desaturation of $18: 2$ to $18: 3$ on membrane glycerolipids, also lower the SA levels in ssi2 plants [40]. To test if fad7 or fad7 fado mutations produced a similar effect as sid2, these mutations were mobilized into the ssi2 eds 1 background. The ssi2 eds 1 fad 7 and ssi2 eds 1 fad7 fado plants were bigger in size compared to $s s i 2$ fad7 or ssi2 fad7 fad8 plants (Figure S3A). The ssi2 eds1 fad7 fad8 were wt- 
A

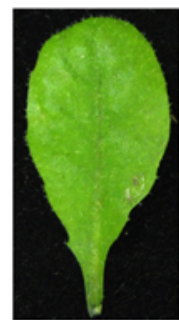

Col-0

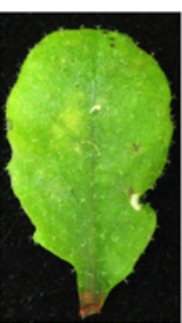

sid2-1

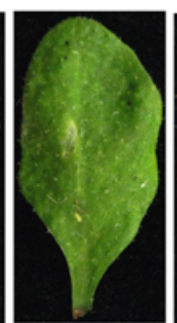

eds1-22

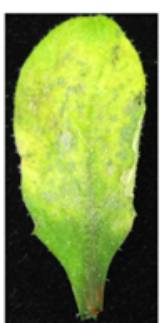

eds1-22 sid2-1

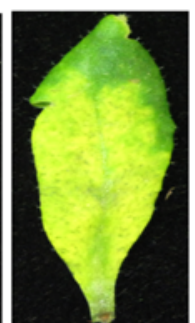

rps2-101c

B

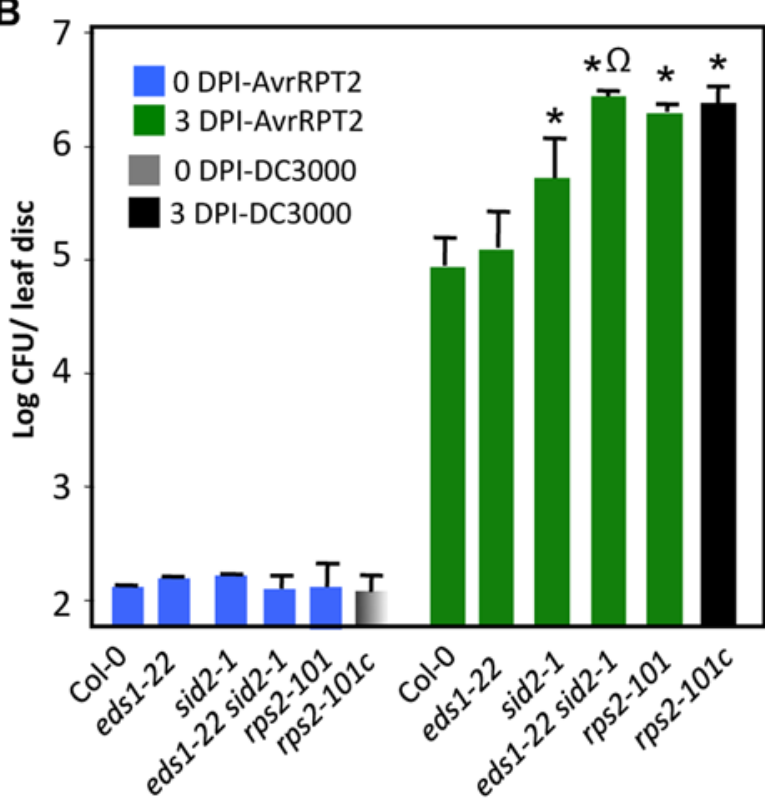

C AvrRPT2

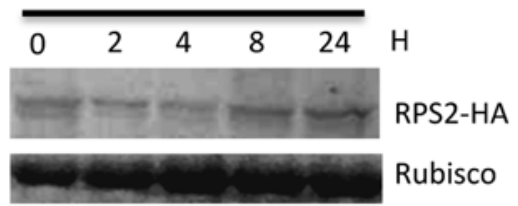

$\mathbf{D}$

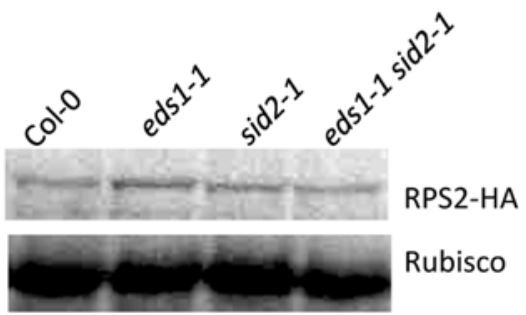

Figure 4. Interaction phenotypes of virulent or AvrRPT2-expressing $P$. syringae with eds1 sid2 plants. (A) Photograph showing phenotypes produced upon infiltration of $10^{5} \mathrm{CFU} / \mathrm{ml}$ bacteria (AvrRPT2). All genotypes were in the Col-0 background. The leaves were photographed at 3 days post inoculation (dpi). The pathogen-inoculated EDS1 SID2 F2 plants showed absence of any visible symptoms in response to bacterial inoculations, similar to Col-0 plants (data not shown). (B) Growth of virulent or avirulent (expressing AvrRPT2) P. syrinage on indicated genotypes. The error bars indicate SD. Asterisks and omega symbols indicate data statistically significant from wt $(\mathrm{Col}-0)$ or sid2 $(\mathrm{P}<0.05, \mathrm{n}=4)$, respectively. All genotypes are in the Col-0 background. (C) Levels of HA-tagged RPS2 protein at 0, 2, 4, 8, and $24 \mathrm{~h}$ post inoculation with P. syringae expressing AvrRPT2. Levels of Rubisco were used as the loading control. (D) Levels of HA-tagged RPS2 protein in indicated genotypes. Levels of Rubisco were used as the loading control. doi:10.1371/journal.pgen.1000545.g004 
A

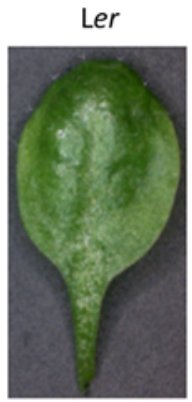

eds1-2 (Ler)

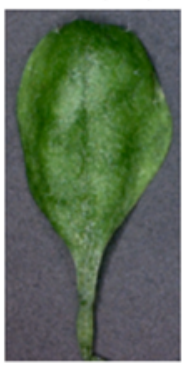

Ler-NahG

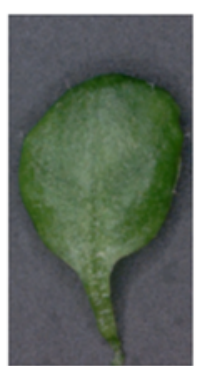

eds1-2 -NahG (Ler)

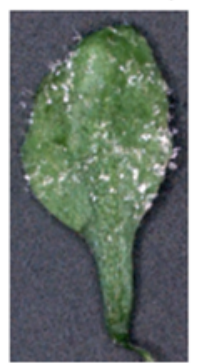

B
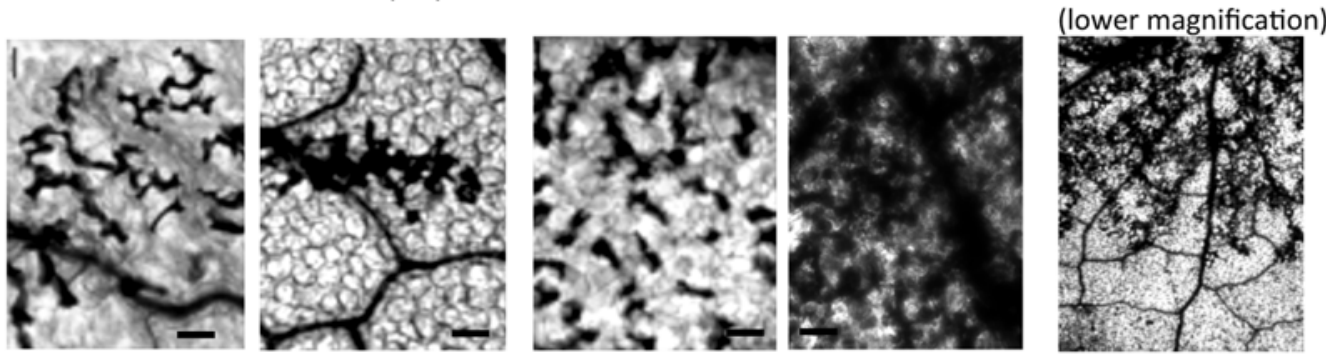

C
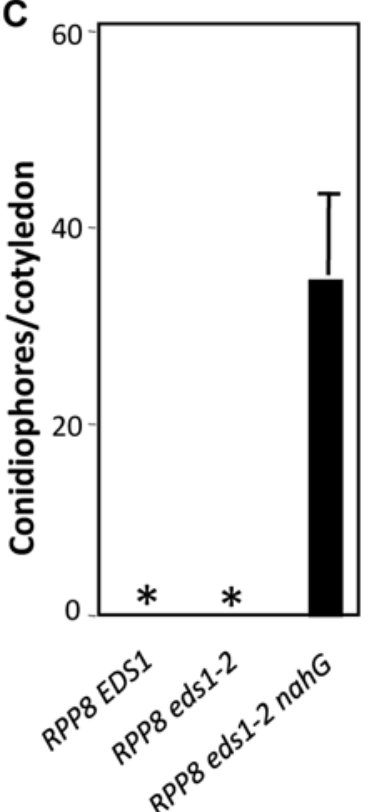
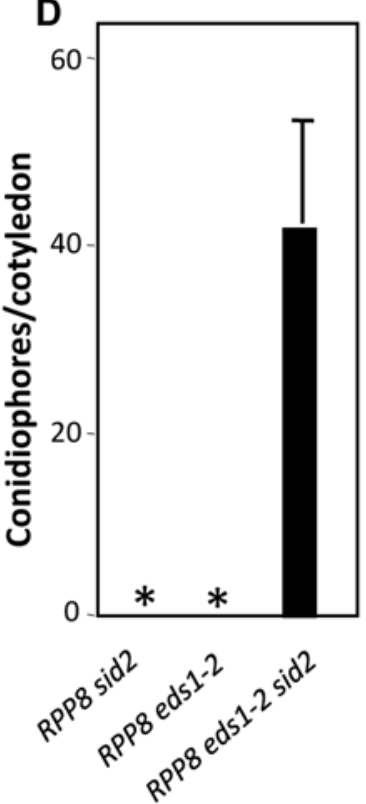

Figure 5. Interaction phenotypes of $H$. arabidopsidis biotype Emco5 expressing Atr8 with RPP8 eds1-2 nahG or RPP8 eds1-2 sid2-1 plants. (A) Whole leaf pictures showing growth of Emco5 on the cotyledons from indicated genotypes. All genotypes were in the Ler background. Cotyledons were photographed 10 days after inoculation. (B) Trypan blue stained leaf showing microscopic HR on Ler and Ler nahG leaves, and trailing necrosis on eds1-2 and eds1-2 nahG leaves (scale bars, 270 microns). Both high (100×) and low magnification (100 $\times$ ) images of eds 1-2 nah leaf are shown. Pathogen inoculations were carried out in F2, F3, and F4 generations with consistent results. The F2 plants showing wt genotype at the mutant locus were resistant to pathogen infection (data not shown). (C) Quantification of pathogen growth on RPP8 EDS1, RPP8 eds 1-2 and RPP8 eds 1-2 nahG plants. Approximately, 40-60 cotyledons were assayed for each genotype. Asterisks indicate absence of spores. All genotypes were in the Ler background. (D) Quantification of pathogen growth on RPP8 sid2, RPP8 eds 1-2, and RPP8 eds1-2 sid2-1 plants. All genotypes were in the ssi2 background. Approximately, 40-60 cotyledons were assayed for each genotype. Asterisks indicate absence of spores.

doi:10.1371/journal.pgen.1000545.g005 
A

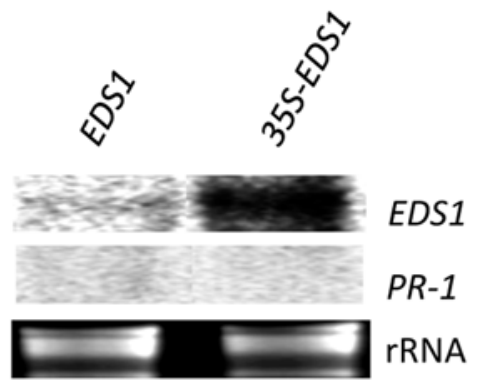

B

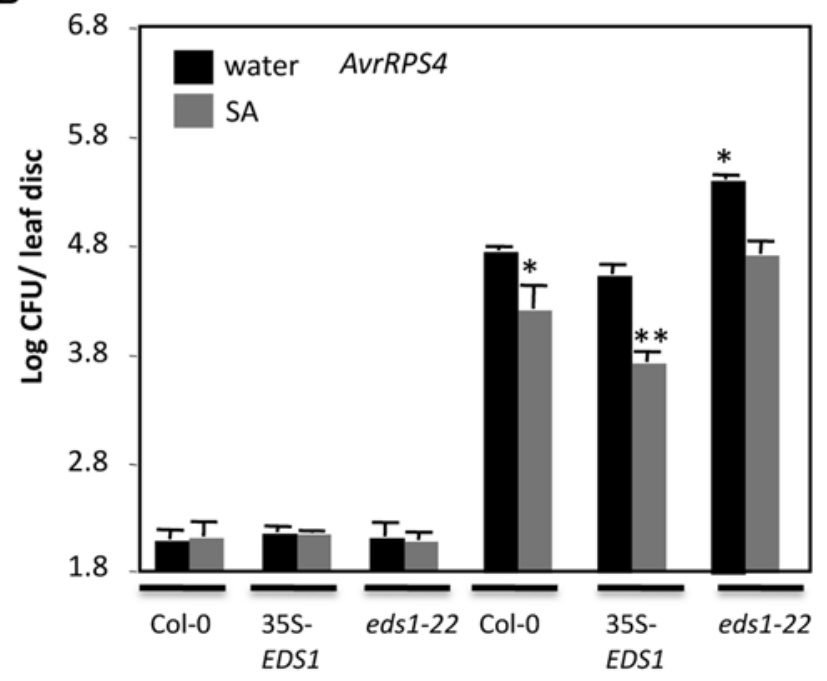

Figure 6. Effect of SA pretreatment and EDS1 overexpression on pathogen resistance. (A) Expression of EDS1 and PR-1 in EDS1 (Col-0) and 35S-EDS1 (Col-0) plants. Total RNA was extracted from 4week-old plants and ethidium bromide staining of rRNA was used as the loading control. (B) Growth of P. syrinage AvrRPS4 on indicated genotypes (all in Col-0 background). Single asterisks indicate data statistically significant from results for water-treated wt (Col-0) $(P<0.05$, $n=4)$. Two asterisks indicate data statistically significant from results for SA-treated wt $(\mathrm{Col}-0)(\mathrm{P}<0.05, \mathrm{n}=4)$. The error bars indicate SD. doi:10.1371/journal.pgen.1000545.g006

like in morphology and showed no or greatly reduced cell death lesions (Figure S3A, S3B). PR-1 expression was greatly reduced or abolished in ssi2 eds 1 fad 7 and ssi2 eds 1 fad 7 fado plants, respectively (Figure S3C) and correlated with their endogenous SA/SAG levels; the ssi2 eds 1 fad7 and ssi2 eds 1 fad7 fado plants showed greatly reduced or basal levels of SA and SAG, respectively (Figure S3D, $\mathrm{S} 3 \mathrm{E}$ ). Expression of some $R$ genes (SSI4, RPS2, RPP5) was nominally or moderately reduced in ssi2 eds 1 fad7 plants (Figure $\mathrm{S} 3 \mathrm{~F})$. By comparison, all $R$ genes tested were expressed at basal levels in ssi2 eds 1 fad7 fad8 plants (Figure S3F). These results showed that presence of $f a d 7 \mathrm{fad} 8$ mutations restored the altered defense phenotypes of ssi 2 eds 1 plants. FA profiling did not detect any significant increase in 18:1 levels in ssi2 eds 1 fad7 and ssi2 eds 1 fad7 fado plants, compared to ssi2 fad7 and ssi2 fad7 fado, respectively (Table S4). This suggested that restoration of defense phenotypes in ssi2 eds 1 fad 7 fado was not the result of restored 18:1 levels, but rather the reduction of SA levels in the eds 1 background.
Mutations in EDS5 and PAD4 also lower SA/SAG levels in ssi2 plants [40]. To determine if mutations in these can substitute for sid2 triple mutants containing ssi2 eds1 pad4 and ssi2 eds1 eds 5 were generated. The ssi2 eds 1 pad4 plants were morphologically similar to ssi2 eds 1 or ssi2 pad4 plants and showed spontaneous cell death and increased expression of $P R-1$ gene (Figure $8 \mathrm{~A}-8 \mathrm{C}$ ). In comparison, ssi2 eds 1 eds 5 showed wt-like morphology, greatly reduced cell death and basal expression of $P R-1$ gene (Figure $8 \mathrm{~A}-$ 8C). Quantification of endogenous SA levels showed that both ssi2 eds1 eds5 and ssi2 eds1 pad4 accumulated lower SA/SAG levels compared to ssi2 eds 5 and ssi2 pad4, respectively (Figure 8D and 8E). However, while ssi2 eds1 eds 5 plants accumulated basal levels of SA/SAG, the ssi2 eds 1 pad4 accumulated significantly higher levels of SA/SAG compared to wt, ssi2 sid2 and ssi2 eds 1 eds 5 plants (Figure $8 \mathrm{D}$ and $8 \mathrm{E}$ ). Analysis of $R$ gene expression showed greatly reduced levels in ssi2 eds 1 eds5 plants but the ssi2 eds1 pad4 expressed ssi2-like levels of $R$ genes (Figure 8F, Figure S1D). Taken together, these results suggest that the suppression of SA levels was required for the normalization of defense phenotypes in the $s s i 2$ eds1 background.

PAD4, SAG101, and EDS5 are not functionally redundant with $S A$ in low 18:1-mediated signaling

Besides EDS1, the SA signaling pathway is also regulated by $P A D 4$ and EDS5 and via the physical association of EDS1 with SAG101 and PAD4 [17,19,45]. To determine if PAD4, SAG101 or EDS5 also function redundantly with SA, we introduced the pad4, sag101 and $e d s 5$ mutations in the ssi2 and ssi2 sid2 backgrounds.

The ssi2 sag101, ssi2 pad4 and ssi2 eds5 plants showed ssi2-like morphology, visible and microscopic cell death and constitutive PR-1 gene expression (Figure S4A, S4B, S4C and Figure S5A, $\mathrm{S} 5 \mathrm{~B}, \mathrm{~S} 5 \mathrm{C})$. Consistent with these phenotypes, the ssi2 sag101, ssi2 pad4, ssi2 eds 5 plants showed increased expression of $R$ genes (Figure S4D and Figure S5D) and accumulated elevated levels of SA and SAG (Figure S4E, S4F and Figure S5E, S5F). Notably, the SA levels in ssi2 sag101 plants were $\sim 6$-fold lower than in ssi2 plants, suggesting that SAG101 contributed to the accumulation of $\mathrm{SA}$ in ssi2 plants. To determine if the reduced SA in the sag101 background could restore wt-like phenotypes in ssi2 eds 1 plants, triple mutant ssi2 eds 1 sag101 plants were generated. Although the ssi2 eds1 sag101 plants accumulated significantly lower levels of SA/SAG (Figure S4E, S4F), these plants were only slightly bigger than ssi2 eds 1 or ssi2 sid2 plants (Figure S4A), showed spontaneous cell death (Figure S4B) and expressed $P R-1$ (Figure S4C) and $R$ genes constitutively (Figure $\mathrm{S} 4 \mathrm{D})$. We next analyzed the triple mutant ssi2 sag101 sid2, ssi2 pad4 sid2 and ssi2 eds5 sid2 plants. All the triple mutants contained wt-like levels of SA and SAG (Figure S4E, S4F and Figure S5E, S5F). The ssi2 sag101 sid2 plants were morphologically similar to ssi2 plants, showed spontaneous cell death and expressed $R$ genes constitutively (Figure S4A, S4B, S4C, S4D). In comparison, the ssi2 pad4 sid2 and ssi2 eds 5 sid2 plants were bigger in morphology. However, plants of both genotypes showed cell death (Figure S5A, S5B) and expressed $R$ genes constitutively (Figure S5D). Together, these data suggest that the functional redundancy with SA was specific only to EDS1 and did not extend to PAD4, SAG101 or EDS5.

\section{Discussion}

SA is long known as an essential modulator of $R$ gene-derived signaling in pathogen defense. Several molecular components, including EDS1, have been identified as essential effectors of SAderived signaling $[23,26,45]$. Since SA upregulates expression of $E D S 1$, both SA and EDS1 are thought to function in a positive 
A
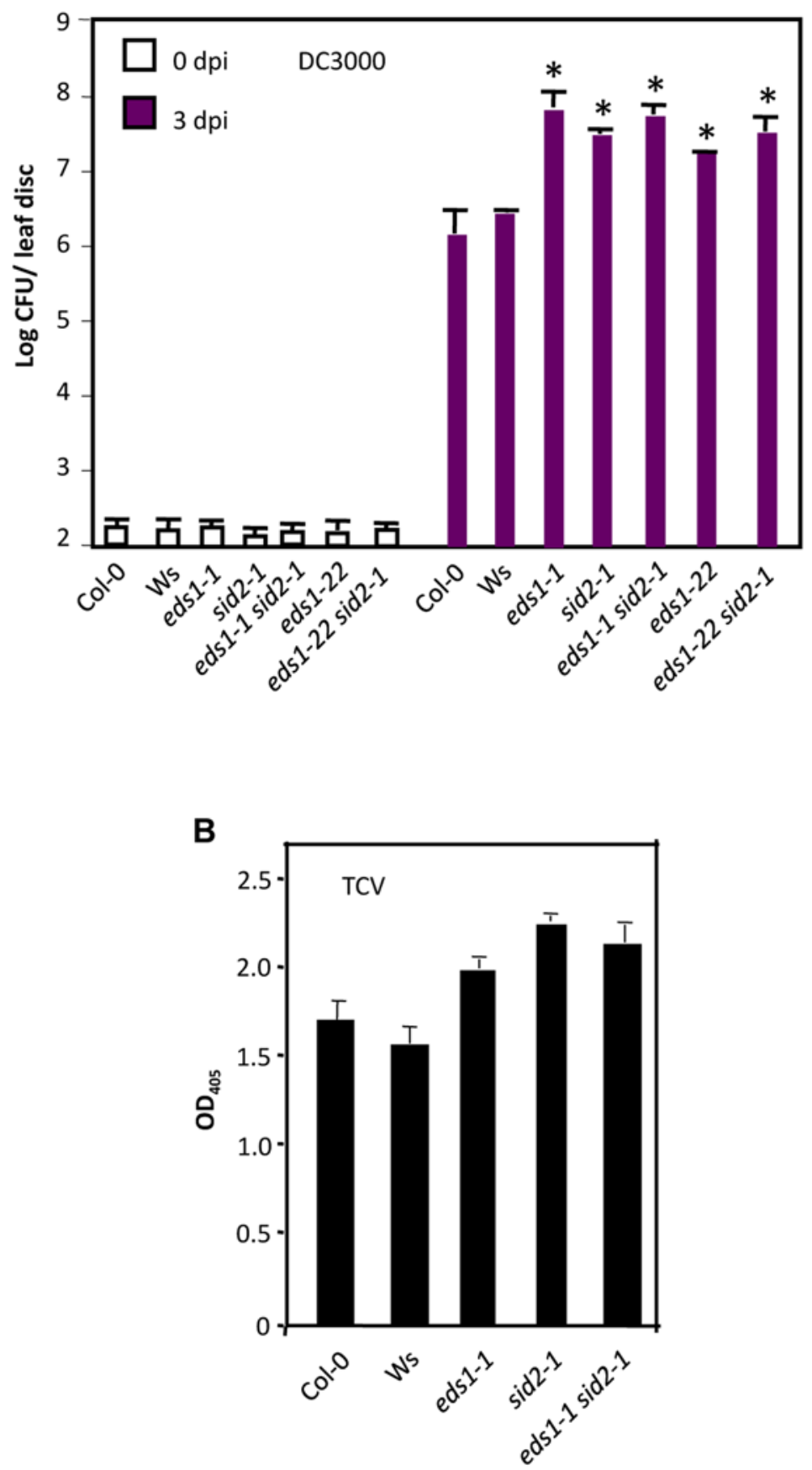

Figure 7. Basal resistance in eds1 sid2 plants. (A) Growth of virulent $P$. syrinage on indicated genotypes. The error bars indicate SD. Asterisks indicate data statistically significant from wt (Col-0 or Ws) $(P<0.05, n=4)$. The eds 1-1 and eds 1-22 are in Ws and Col-0 ecotypic backgrounds, respectively. (B) ELISA showing levels of TCV CP in the inoculated leaves of indicated genotypes at 3 dpi. The error bars indicate SD ( $n=4)$. doi:10.1371/journal.pgen.1000545.g007

feedback loop and EDS1 is widely considered an upstream effector of SA $[16,19,23,45]$. Recent data has shown that EDS1 signals resistance via both SA-dependent as well as SA-independent pathways [46]. Strikingly, EDS1-dependent but SA-independent branch of EDS1 pathway still requires SA pathway for full expression of resistance [46]. In this study, we have characterized the relationship between EDS1 and SA. We show that the two components act in a redundant, and not necessarily sequential manner to regulate $R$ gene expression induced in response to a reduction in the levels of the FA 18:1. Furthermore, EDS1 and SA also function redundantly in $R$ gene-mediated defense against viral, bacterial and oomycete pathogens. It appears that the redundant functions of EDS1 and SA may have prevented their identification as required components for signaling mediated by CG-NBS-LRR R proteins. Indeed, RPS2-mediated signaling is fully compromised only in $e d s 1$ sid 2 and not in the single mutant 
A

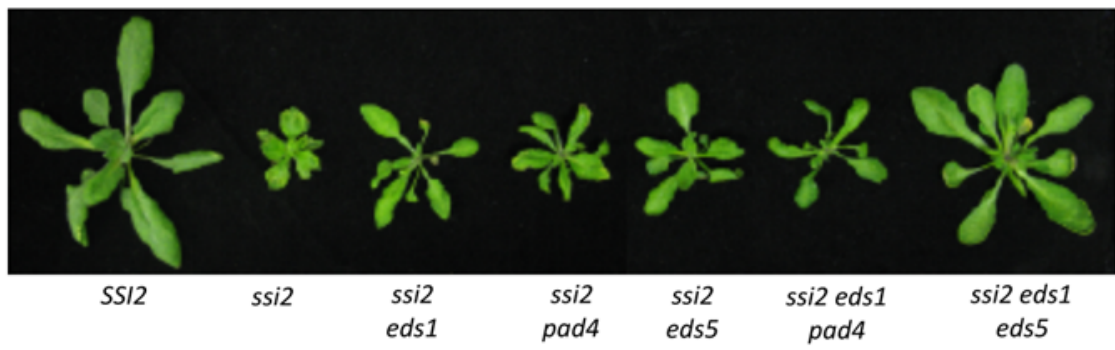

B

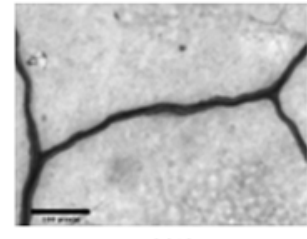

SSI2

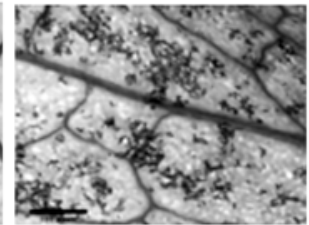

ssi2 eds5

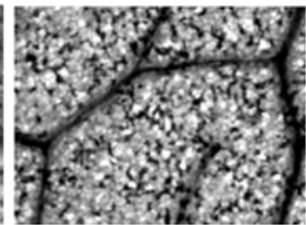

ssi2 eds1 pad4

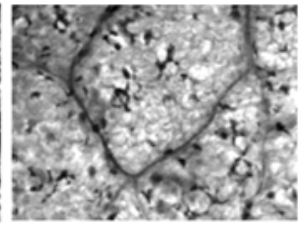

ssi2 eds1 eds5

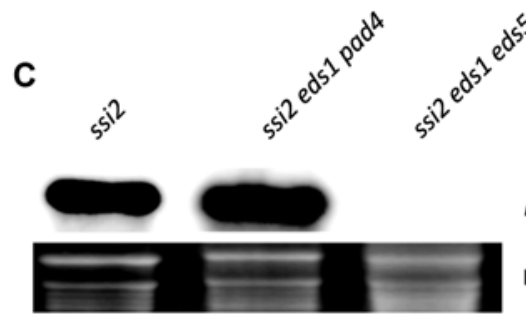

$P R-1$

rRNA
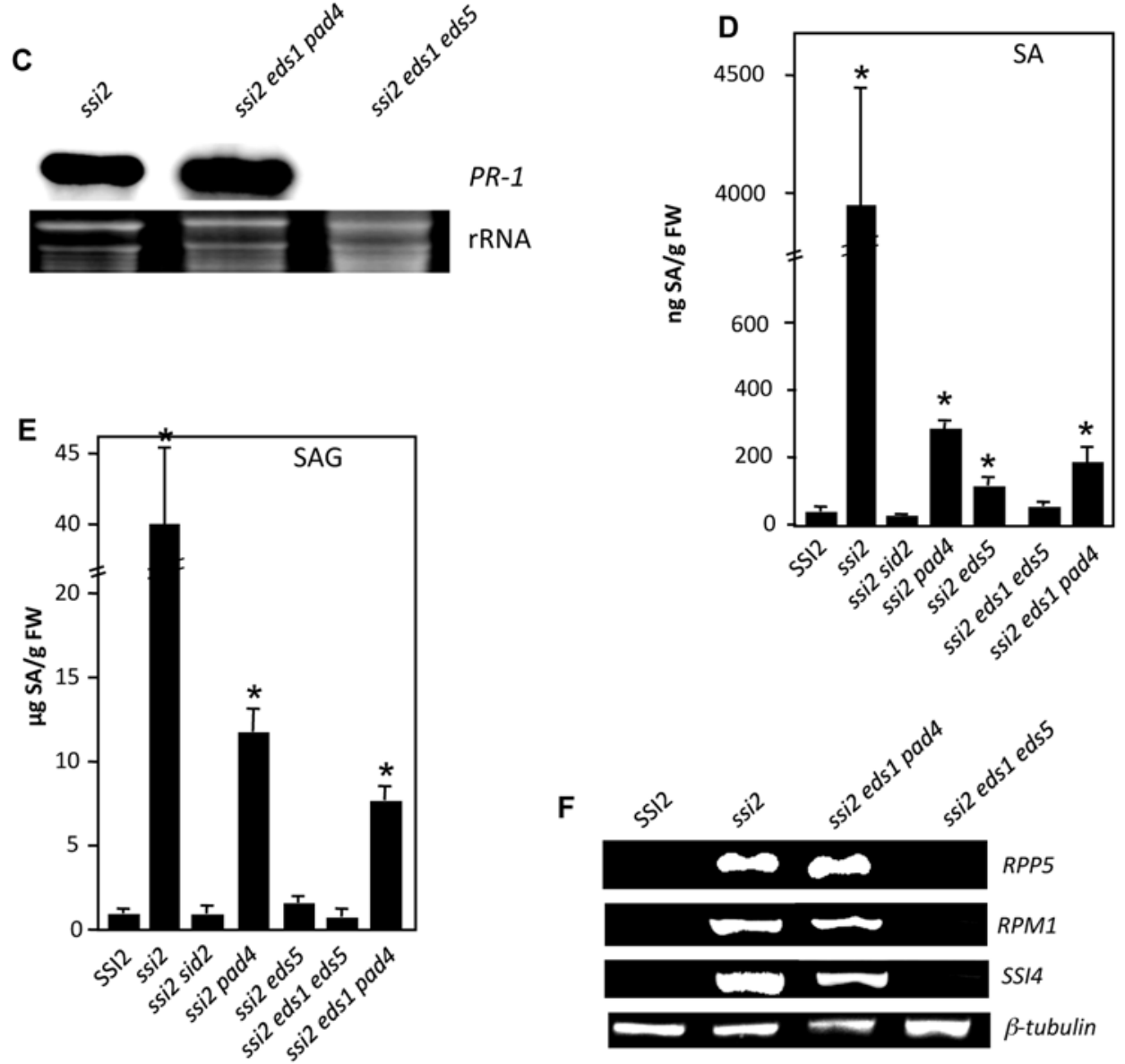

Figure 8. Morphology, cell death, SA/SAG levels. $P R-1$ and $R$ gene expression ssi2 eds 1-2 pad4-1 and ssi2 eds1-2 eds5-1 plants. (A) Comparison of the morphological phenotypes displayed by 4-week-old soil-grown wt (SSI2), ssi2, ssi2 eds1, ssi2 pad4, ssi2 eds5, ssi2 eds 1 pad4, and ssi2 eds 1 eds5 plants. (B) Microscopy of trypan blue-stained leaves from indicated genotypes. (C) Expression of PR-1 gene in indicated genotypes. Total RNA was extracted from 4-week-old plants and used for RNA gel-blot analysis. Ethidium bromide staining of rRNA was used as the loading control. (D) Endogenous SA levels in the leaves of 4-week-old soil-grown plants. Values are presented as mean of three replicates and the error bars represent SD. Statistical significance was determined using Students $t$-test. Asterisks indicate data statistically significant compared to SSI2 (Col-0) plants $(P<0.05$, $n=5$ ). (E) Endogenous SAG levels in the leaves of 4-week-old soil-grown plants. Values are presented as mean of three replicates and the error bars represent SD. Asterisks indicate data statistically significant compared to SS/2 (Col-0) plants ( $P<0.05, \mathrm{n}=5)$. (F) RT-PCR analysis of $R$ genes in indicated genotypes. The level of $\beta$-tubulin was used as an internal control to normalize the amount of CDNA template. The SSI2 EDS1, SSI2 PAD4, SSI2 EDS1 $P A D 4$, and SSI2 EDS1 EDS5 F2 plants showed wt-like morphology, accumulated basal levels of SA and showed basal level expression of $P R-1$ and $R$ genes (data not shown).

doi:10.1371/journal.pgen.1000545.g008 
plants. Similarly, HRT-mediated signaling leading to HR formation and PR-1 gene expression is only affected in eds 1 sid2 plants, while eds 1 or sid 2 plants behave similar to wt plants. Furthermore, RPPO-mediated resistance, which was previously reported not to require EDS1 or SA $[21,24]$, is compromised in plants lacking both EDS1 and SA. In contrast to their effect on $R$ gene-mediated resistance, loss of both EDS1- and SA-dependent signals did not additively lower basal resistance to $P$. syringae or TCV. Together, these data suggests that the redundant functions of EDS1 and SA might be relevant only for $R$ gene-mediated signaling.

In contrast to SA application, overexpression of EDS1 was unable to confer increased resistance to the avirulent pathogen $P$. syringae. Furthermore, unlike SA, overexpression of EDS1 was not associated with the induction of $P R-1$ gene expression. These findings, together with the observation that SA was able to induce EDS1 expression and that SA application on wt plants resulted in higher resistance than that in eds1, suggests that SA feedback regulates EDS1-derived signaling in a unidirectional manner (Figure 9B). Thus, SA application induces both SA- and EDS1derived signaling, the additive effects of which enhance resistance in wt plants much more than in eds 1-22 plants. Furthermore, the combined effects of SA pretreatment and EDS1 overexpression induced much better resistance than the individual effects of each. This is consistent with a previous report that 35S-EDS1 plants induce rapid and stronger expression of $P R-1$ in response to pathogen inoculation [47]. The additive effects of EDS1 and SA was also supported by the observation that eds 1 sid 2 plants showed pronounced chlorosis upon inoculation with AvrRPS4 expressing pathogen, which is recognized by a TIR-NBS-LRR protein RPS4 (Figure S2B). Since mutations in SA-independent branch of EDS1 pathway and sid 2 have additive effects on $R$ gene-mediated resistance [46], it is possible that overexpression of EDS1 triggers signaling via both SA-dependent and/or -independent branches of EDSl pathway.

Although the Col-0 ecotype is thought to contain two functional alleles of EDS1 [26], a KO mutation in At3g48090 was sufficient to compromise both basal and $R$ gene (RPS4)-mediated resistance. However, the Col-0 eds1-22 mutant consistently supported less growth of virulent or avirulent pathogens compared to eds1-1 or eds1-2 plants. This suggests that the second EDS1 allele in the Col0 ecotype might also contribute towards the resistance response. This is consistent with another study where constitutive defense phenotypes due to the overexpression of the SNC1 gene, encoding a TIR-NBS-LRR R protein, are not completely suppressed by a mutation in eds 1 in the Col-0 background but restored by the eds 1 mutation in the Ws background [48].

The inability to accumulate SA together with a mutation in EDS1 was also required to suppress constitutive defense signaling resulting from the overexpression of $R$ genes induced in response to reduced 18:1 levels. Although eds 1 or sid2 plants were entirely competent in inducing $R$ gene expression in response to a reduction in 18:1, eds1 sid2 plants were not. Thus, ssi2 eds1 sid2 as well as glycerol-treated $e d s 1$ sid 2 plants showed wt-like expression of $R$ genes while $s s i 2$ eds 1 , ssi2 sid2 and glycerol-treated $e d s 1$ or $s i d 2$ plants showed increased expression of $R$ genes. Moreover, treatment of ssi2 eds 1 sid2 plants with exogenous SA restored $R$ transcript induction and cell death in these plants. The fact that glycerol treatment is unable to induce $R$ gene expression in $e d s 1$ sid2 plants supports the possibility that EDS1 and SA function upstream of, and not merely serve as a feedback loop in, $R$ gene induction. Signaling induced by low 18:1 levels continues to function in the absence of SA, suggesting a novel SA-independent role for EDS1 in defense signaling.
A

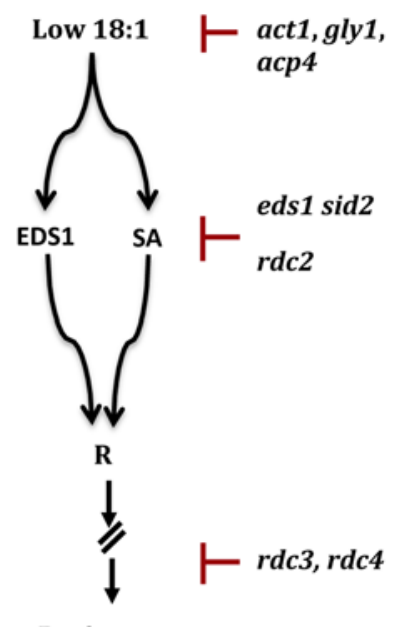

B

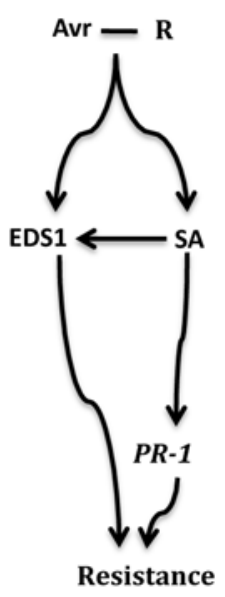

Figure 9. Models for signaling induced by low 18:1 fatty acid levels and $\boldsymbol{R}$ genes. (A) EDS1 and SA function upstream of $R$ genes and regulate expression of $R$ genes induced by low 18:1 fatty acid levels. Mutations in EDS1 and SA-synthesizing enzyme, encoded by $S I D 2$, abolish constitutive upregulation of $R$ genes and associated enhanced resistance in genetic backgrounds containing low 18:1 levels. Similar to EDS1/SA, restored in defective crosstalk (RDC) 2 acts downstream of signaling induced by low levels of 18:1 but upstream of $R$ gene expression. Signaling induced by low 18:1 fatty acid levels can also be suppressed by mutations in ACT1-encoded G3P acyltransferase [30], GLY1-encoded G3P dehydrogenase [31], or ACP4-encoded acyl carrier protein 4 [35], which normalize 18:1 levels, or by blocking steps downstream of $R$ gene expression ( $r d c 3$ and $r d c 4)$ ). Upregulation of $R$ genes induced by low 18:1 fatty acid levels does not require PAD4, SAG101, or EDS5, which are components of the resistance signaling pathway(s) initiated upon R-Avr interaction. (B) Direct or indirect interaction between host-encoded $R$ and pathogen-encoded Avr products initiate resistance signaling, which requires EDS1 and SA. Exogenous application of SA induces expression of $P R-1$ and EDS1 genes but overexpression of EDS1 does not induce $P R-1$ expression or increase SA levels. The EDS1- and SA-dependent pathways have additive effects.

doi:10.1371/journal.pgen.1000545.g009

Since ssi2 eds 1 sid2 plants contain a mixed ecotypic background (Nö, Ws/Ler, Col-0, ecotypes), it is possible that ecotypic variations in various genetic backgrounds resulted in the restoration of ssi2triggered defense phenotypes. Indeed, phenotypic variations amongst different Arabidopsis ecotypes have been associated with many physiological processes [48-51]. Moreover, certain alleles can express themselves only in specific ecotypic backgrounds [48,51]. However, since ssi2 EDS1 SID2, ssi2 EDS1 sid2 or ssi2 eds1 SID2 plants (F2 population) always exhibited ssi2-like phenotypes, it is highly unlikely that ecotypic variations resulted in the restoration of phenotypes in ssi2 eds 1 sid2 plants. The effect of ecotypic variations on the observed phenotypes can be further ruled out for the following reasons. First, the effects of different mutations were assessed in multiple backgrounds. For example, we used both $e d s 1-1$ (Ws-0 ecotype) and $e d s 1-2$ (Ler ecotype) alleles in ssi2 sid2 (Nö, Col-0 ecotypes) and ssi2 nahG (Nö ecotype) backgrounds and all combinations of ssi2 with eds1-1/eds1-2 and sid $2 / n a h G$ produced similar phenotypes (Table S1). Second, all defense phenotypes were assessed over three generations using multiple progeny. Third, similar results were obtained when different ecotypic backgrounds were evaluated for their response to different pathogens. For example, eds 1 nahG or eds 1 sid2 backgrounds conferred increased susceptibility to $H$. arabidopsidis, 
P. syringae and TCV, even though only the genotypes used for TCV were of mixed ecotypic backgrounds. Fourth, F2 plants containing wild-type alleles behaved like wild-type parents. Finally, the effects of various mutant backgrounds on ssi2 phenotypes were also confirmed by glycerol application on individual mutants.

Although glycerol treatment failed to induce $R$ gene expression in $e d s 1$ sid 2 plants, it did induce cell death. This is in contrast to the absence of a cell death phenotype in ssi2 eds1 sid2 leaves. One possibility is that the glycerol-triggered cell death is not due to a reduction in 18:1 levels. However, significant overlap between ssi2and exogenous glycerol-triggered signaling pathways lessens such a possibility [40]. An alternate possibility is that, while EDS1 affects a majority of the responses induced by low 18:1 levels, the cell death phenotype is also governed by some additional molecular factor(s). This is supported by the fact that ssi2 pad4 sid2 plants exhibit improved morphology and reduced cell death even though they are not restored for other defense-related phenotypes.

Since the overexpression of $R$ genes can initiate defense signaling in the absence of a pathogen $[48,52]$, it is possible that the induced defense responses in $s s i 2$ plants are the result of increased $R$ gene expression. This idea is supported by the fact that ssi2-related phenotypes can be normalized by restoring $R$ gene expression to wtlike levels, irrespective of their 18:1 levels. Thus, wt-like defense phenotypes are restored in suppressors containing high 18:1 levels, such as ssi2 act1, ssi2 gly 1 or ssi2 acp4 [30,31,35], as well as in suppressor containing low 18:1 levels, such as ssi2 eds1 sid2 (this work) and restored in defective crosstalk $(r d c) 2$ (unpublished data) (Figure 9A). We have also characterized additional ssi2 suppressors that show wt-like phenotypes even though they contain low 18:1 levels and express $R$ genes constitutively $(r d c 3, r d c 4)$. Together, these results suggest that the ssi2-associated phenotypes can be restored by normalizing $R$ gene expression to wt-like levels either by increasing 18:1 levels, impairing factors downstream of signaling induced by low 18:1 levels, or impairing events downstream of $R$ gene expression induced by low 18:1 levels.

In addition to 18:1 levels or $R$ gene expression, ssi2-related defense signaling could also be normalized by altering some factor(s) that function downstream of $R$ gene induction. Indeed, our preliminary characterizations have identified additional ssi2 suppressors that yield wt-like phenotypes with regards to defense signaling but continue to express $R$ genes at high levels. Reduced 18:1 levels may induce defense signaling by directly regulating the transcription of activators or suppressors of defense gene expression. This is supported by the fact that 18:1-mediated activation of a transcription factor induces the expression of genes required for neuronal differentiation [53]. Similarly, in Sacharromyces cerevisiae as well as mammalian cells, binding of 18:1 to specific transcription factors induces the transcription of genes carrying 18:1 responsive elements in their promoters [54,55]. On the other hand, expression of the oncogene HER2 is inhibited via the 18:1-upregulated expression of its transcriptional repressor [56]. Reduced 18:1 might also directly activate/inhibit/alter protein activities. For example, 18:1 is known to activate the Arabidopsis phospholipase D [57] and inhibit glucose-6-phosphate transporter activity in Brassica embryos [58]. Indeed, we have also identified several Arabidopsis proteins for which enzymatic activities are inhibited upon binding to 18:1 (unpublished data).

In conclusion, results presented here redefine the currently accepted pathway for SA-mediated signaling by showing that EDS1 and SA play a redundant role in plant defense mediated by $\mathrm{R}$ proteins and in signaling induced by low 18:1 fatty acid levels. Further biochemical characterization should help determine if 18:1 binds to EDS1 and if cellular levels of 18:1 modulate the as yet undetected lipase activity of EDS1.

\section{Materials and Methods}

\section{Plant growth conditions and genetic analysis}

Plants were grown in MTPS 144 Conviron (Winnipeg, MB, Canada) walk-in-chambers at $22^{\circ} \mathrm{C}, 65 \%$ relative humidity and 14 hour photoperiod. The photon flux density of the day period was $106.9 \mu$ moles $\mathrm{m}^{-2} \mathrm{~s}^{-1}$ and was measured using a digital light meter (Phytotronic Inc, Earth city, MO). All crosses were performed by emasculating the flowers of the recipient genotype and pollinatng with the pollen from the donor. All the genotypes and crosses analyzed in this work, their genetic background and number of single, double, or triple mutant plants studied are listed in Table S1. In most cases, single, double, or triple mutant plants were obtained from more than one combination of crosses and showed similar morphological, molecular and biochemical phenotypes. F2 plants showing the wt genotype at the mutant locus were used as controls in all experiments. The wt and mutant alleles were identified by PCR, CAPS, or dCAPS analysis and/or based on the FA profile $[30,31,38,40]$. The EDS1 KO mutant in At3g48090 was, isolated by screening SALK_071051 insertion line, obtained from ABRC. The EDS1 KO was designated eds1-22, based on the previous designation assigned to SALK_071051 T-DNA KO line [48]. The At3g48090 gene showed $98.8 \%$ identity at amino acid level to EDS1 allele from Ler ecotype. The homozygous insertion lines were verified by sequencing PCR products obtained with primers specific for the TDNA left border in combination with an EDS1-specific primer. The eds1-22 lines did not show any detectable expression of EDS1.

\section{RNA extraction and northern analyses}

Small-scale extraction of RNA from one or two leaves was performed with the TRIzol reagent (Invitrogen, CA), following the manufacturer's instructions. Northern blot analysis and synthesis of random-primed probes for $P R-1$ and $P R-2$ were carried out as described previously [29].

\section{Reverse Transcription-PCR}

RNA quality and concentration were determined by gel electrophoresis and determination of $\mathrm{A}_{260}$. Reverse transcription (RT) and first strand cDNA synthesis were carried out using Superscript II (Invitrogen, CA). Two-to-three independent RNA preparations were used for RT-PCR and each of these were analyzed at least twice by RT-PCR. The RT-PCR was carried out for 35 cycles in order to determine absolute levels of transcripts. The number of amplification cycles was reduced to 21-25 in order to evaluate and quantify differences among transcript levels before they reached saturation. The amplified products were quantified using ImageQuant TL image analysis software (GE, USA). Gene-specific primers used for RT-PCR analysis are described in Table S5.

\section{Trypan-blue staining}

The leaves were vacuum-infiltrated with trypan-blue stain prepared in $10 \mathrm{~mL}$ acidic phenol, $10 \mathrm{~mL}$ glycerol, and $20 \mathrm{~mL}$ sterile water with $10 \mathrm{mg}$ of trypan blue. The samples were placed in a heated water bath $\left(90^{\circ} \mathrm{C}\right)$ for $2 \mathrm{~min}$ and incubated at room temperature for $2-12 \mathrm{~h}$. The samples were destained using chloral hydrate $(25 \mathrm{~g} / 10 \mathrm{~mL}$ sterile water; Sigma), mounted on slides and observed for cell death with a compound microscope. The samples were photographed using an AxioCam camera (Zeiss, Germany) and images were analyzed using Openlab 3.5.2 (Improvision) software.

\section{Pathogen infections}

The asexual conidiospores of $H$. arabidopsidis Emco5 expressing Atr 8 were maintained on the susceptible host Nössen (Nö) or Nö 
$\mathcal{N a h G}$. The spores were removed by agitating the infected leaves in water and suspended to a final concentration of $10^{5}$ spores $/ \mathrm{mL}$. Two-week-old seedlings were sprayed with spore suspension and transferred to a MTR30 reach-in chamber (Conviron, Canada) maintained at $17^{\circ} \mathrm{C}, 98 \%$ relative humidity and $8 \mathrm{~h}$ photoperiod. Plants were scored at $\sim 10-14 \mathrm{dpi}$ and the conidiophores were counted under a dissecting microscope.

The bacterial strain DC3000 derivatives containing pVSP61 (empty vector), AvrRpt2 or AvrRps 4 were grown overnight in King's $\mathrm{B}$ medium containing rifampicin (Sigma, MO). The bacterial cells were harvested, washed and suspended in $10 \mathrm{mM} \mathrm{MgCl}$. The cells were diluted to a final density of $10^{5}$ to $10^{7} \mathrm{CFU} / \mathrm{mL}\left(\mathrm{A}_{600}\right)$ and used for infiltration. The bacterial suspension was injected into the abaxial surface of the leaf using a needle-less syringae. Three leaf discs from the inoculated leaves were collected at 0 and 3 dpi. The leaf discs were homogenized in $10 \mathrm{mM} \mathrm{MgCl}_{2}$, diluted $10^{3}$ or $10^{4}$ fold and plated on King's B medium.

Transcripts synthesized in vitro from a cloned cDNA of TCV using T7 RNA polymerase were used for viral infections [59,60]. For inoculations, the viral transcript was suspended at a concentration of $0.05 \mu \mathrm{g} / \mu \mathrm{L}$ in inoculation buffer, and the inoculation was performed as described earlier [56]. After viral inoculations, the plants were transferred to a Conviron MTR30 reach-in chamber maintained at $22^{\circ} \mathrm{C}, 65 \%$ relative humidity and 14 hour photoperiod. HR was determined visually three-to-four days post-inoculation (dpi). Resistance and susceptibility was scored at 14 to $21 \mathrm{dpi}$ and confirmed by northern gel blot analysis. Susceptible plants showed stunted growth, crinkling of leaves and drooping of the bolt.

\section{Transcriptional profiling}

Total RNA isolated from four-week-old plants using TRIZOL as outlined above. The experiment was carried out in triplicate and a separate group of plants was used for each set. RNA was processed and hybridized to the Affimetric Arabidopsis ATH1 genome array GeneChip following the manufacturers instructions (http://www.affymetrix.com/Auth/support/downloads/manuals/ expression_analysis_technical_manual.pdf). All probe sets on the Genechips were assigned hybridization signal above background using Affymetrix Expression Console Software v1.0 (http://www.affymetrix.com/Auth/support/downloads/manuals/ expression_console_userguide.pdf). Data was analyzed by one-way Anova followed by post hoc two sample $t$-tests. The $\mathrm{P}$ values were calculated individually and in pair-wise combination for each probe set. The identities of 162 NBS-LRR genes were obtained from the Arabidopsis information resource (TAIR; www.arabidopsis.org) and disease resistance gene homolog databases (http://niblrrs. ucdavis.edu/).

\section{Fatty acid profiling}

FA analysis was carried out as described previously [61]. For FA profiling, one or few leaves of four-week-old plants were placed in $2 \mathrm{ml}$ of $3 \% \mathrm{H}_{2} \mathrm{SO}_{4}$ in methanol containing $0.001 \%$ butylated hydroxytoluene (BHT). After 30 minutes incubation at $80^{\circ} \mathrm{C}, 1 \mathrm{~mL}$ of hexane with $0.001 \%$ BHT was added. The hexane phase was then transferred to vials for gas chromatography (GC). One-microliter samples were analyzed by GC on a Varian FAME $0.25 \mathrm{~mm} \times 50 \mathrm{~m}$ column and quantified with flame ionization detection. The identities of the peaks were determined by comparing the retention times with known FA standards. Mole values were calculated by dividing peak area by molecular weight of the FA.

\section{SA and SAG quantification}

$\mathrm{SA}$ and SAG quantifications were carried out from $\sim 300 \mathrm{mg}$ of leaf tissue as described before [23].

\section{Chemical treatment of plants}

SA treatments were carried out by spraying or subirrigating 3week-old plants with $500 \mu \mathrm{M}$ SA or $100 \mu \mathrm{M}$ BTH. For glycerol treatment, plants were sprayed with $50 \mathrm{mM}$ solution prepared in sterile water.

\section{Enzyme linked immuno-sorbent assay and western analysis}

Total protein was extracted in buffer containing $50 \mathrm{mM}$ Tris $\mathrm{pH}$ 8.0, $1 \mathrm{mM}$ EDTA, $12 \mathrm{mM} \quad \beta$-mercaptoethanol and $10 \mu \mathrm{g} \mathrm{ml}^{-1}$ phenylmethylsulfonyl fluoride. Proteins were fractionated on a $10-12 \%$ SDS-PAGE to confirm the quality. An antigencoated enzyme-linked immunosorbent assay was used to determine levels of TCV CP in the infected plants as described before [62].

For protein gel blot analysis, leaf tissue from 4-week-old plants was extracted with a buffer containing $50 \mathrm{mM}$ Tris-HCl, $\mathrm{pH} 7.5$, $10 \%$ glycerol, $150 \mathrm{mM} \mathrm{NaCl}, 10 \mathrm{mM} \mathrm{MgCl}_{2}, 5 \mathrm{mM}$ EDTA, $5 \mathrm{mM}$ DTT, and $1 \times$ proteinase inhibitor (Sigma). Protein concentrations were determined by the Bradford assay (Bio-Rad, CA). For immunodetection, $10-50-\mu \mathrm{g}$ protein samples were electrophoresed on $10-15 \%$ polyacrylamide gels and run in the presence of $0.38 \mathrm{M}$ Tris and $0.1 \%$ SDS. Proteins were transferred from the gels to polyvinylidene difluoride membranes by electroblotting, incubated with primary anti-HA antibody (Sigma) and alkaline phosphatase-conjugated secondary antibody (Sigma). Immunoblots were developed using color detection.

\section{Supporting Information}

Figure S1 Relative expression levels of $R$ genes in indicated genotypes. One representative quantification is shown for each Figure (noted above the graph) showing RT-PCR results. The $R$ gene transcript levels were normalized for $\beta$-tubulin and relative differences in expression levels were quantified using ImageQuant TL image analysis software (GE, USA). Two-to-three independent RNA preparations were used for RT-PCR and each of these were analyzed at least twice by RT-PCR. The fold differences in expression levels were consistent between experiments and between repeats within an experiment.

Found at: doi:10.1371/journal.pgen.1000545.s001 (0.16 MB TIF)

Figure S2 Interaction phenotypes of AvrRPT2 or AvrRPS4 expressing $P$. syringae with $e d s 1$ sid2 plants. (A) Photograph showing phenotypes produced upon infiltration of $10^{5} \mathrm{CFU} / \mathrm{ml}$ bacteria (AvrRPT2). The leaves were photographed at 3 days post inoculation (dpi). The mock- or pathogen-inoculated EDS1 SID2 F2 plants showed absence of any visible symptoms in response to bacterial inoculations, similar to Col-0 or Ws-0 plants (data not shown). (B) Photograph showing phenotypes produced upon infiltration of $10^{5} \mathrm{CFU} / \mathrm{mL}$ bacteria. The leaves were photographed at 3 dpi. The phenotypes seen on pathogen inoculated eds1-1 sid2-1 leaves were comparable to those seen on RLD (ecotype) plants, which lack a functional RPS4 gene (data not shown). The mock- or pathogen -inoculated EDS1 SID2 F2 plants showed absence of any visible symptoms in response to bacterial inoculations, similar to Col-0 or Ws-0 plants (data not shown). Found at: doi:10.1371/journal.pgen.1000545.s002 (1.09 MB TIF)

Figure S3 Morphology, cell death, $P R-1$, and $R$ gene expression and SA/SAG levels in ssi2 eds1-2 fad7-1 and ssi2 eds1-2 fad7-1 fad8-1 plants. (A) Comparison of the morphological phenotypes displayed by 4-week-old soil-grown wt (SSI2), ssi2, ssi2 eds1, ssi2 fad7, ssi2 fad7 fado, ssi2 eds1 fad7, and ssi2 eds1 fad7 fado plants. (B) Microscopy of trypan blue-stained leaves from indicated genotypes. (C) Expression of $P R-1$ indicated genotypes. Total RNA was 
extracted from 4-week-old plants and used for RNA gel-blot analysis. Ethidium bromide staining of rRNA was used as loading control. (D) Endogenous SA levels in the leaves of 4-week-old plants. Values are presented as mean of three replicates and the error bars represent SD. Statistical significance was determined using Student's $t$-test. Asterisks indicate data statistically significant between ssi2 fad7 and ssi2 eds 1 fad7 or ssi2 fad7 fado and ssi2 eds 1 fad7 fado $(\mathrm{P}<0.05, \mathrm{n}=5)$. (E) Endogenous SAG levels in the leaves of 4-week-old plants. Values are presented as mean of three replicates and the error bars represent SD. Asterisks indicate data statistically significant between $s s i 2 \mathrm{fad} 7$ and $s s i 2$ eds 1 fad 7 or $s s i 2$ fad7 fado and ssi2 eds1 fad7 fado $(\mathrm{P}<0.05, \mathrm{n}=5)$. (F) RT-PCR analysis of $R$ genes in indicated genotypes. The level of $\beta$-tubulin was used as an internal control to normalize the amount of cDNA template. The SSI2 EDS1 FAD7 and SSI2 EDS1 FAD7 FAD8 F2 plants showed wt-like morphology and basal levels expression of $P R-1$ and $R$ genes (data not shown).

Found at: doi:10.1371/journal.pgen.1000545.s003 (0.96 MB TIF)

Figure S4 Morphology, cell death, $P R-1$, and $R$ gene expression and SA/SAG levels in ssi2 sag101-1, ssi2 sag101-1 eds1-2 and ssi2 sag101-1 sid2-1 plants. (A) Comparison of the morphological phenotypes displayed by 4-week-old soil-grown wt (SSI2; Col-0 ecotype), sag101, ssi2, ssi2 sag101, ssi2 sid2, ssi2 sag101 sid2, ssi2 eds1 and ssi2 sag101 eds 1 plants (scale, $0.5 \mathrm{~cm}$ ). (B) Microscopy of trypan blue-stained leaves from indicated genotypes (scale bars, 270 microns). (C) Expression of $P R-1$ in indicated genotypes. Total RNA was extracted from 3-week-old plants and used for RNA gel-blot analysis. Ethidium bromide staining of rRNA was used as the loading control. (D) RT-PCR analysis of $R$ genes in indicated genotypes. The level of $\beta$-tubulin was used as an internal control to normalize the amount of cDNA template. (E) Endogenous SA levels in the leaves of 4-week-old soil-grown plants. Values are presented as averages of four replicates and the error bars represent SD. (F) Endogenous SAG levels in the leaves of 4-weekold soil-grown plants. Error bars represent SD. The SSI2 SAG101, SSI2 EDS1 SAG101 and SSI2 SAG101 SID2 F2 plants showed wtlike morphology, accumulated wt-like levels of SA and showed wtlike expression of $P R-1$ and $R$ genes (data not shown). Statistical significance in $(\mathrm{E})$ and $(\mathrm{F})$ were determined using Student's $t$-test. Asterisks indicate data statistically significant compared to results from SSI2 (Col-0) plants $(\mathrm{P}<0.05, \mathrm{n}=4)$.

Found at: doi:10.1371/journal.pgen.1000545.s004 (1.17 MB TIF)

Figure S5 Morphology, cell death, $P R-1, \mathrm{SA} / \mathrm{SAG}$ levels, and $R$ gene expression in ssi2 pad4-1 sid2-1 and ssi2 eds5-1 sid2-1 plants. (A) Comparison of the morphological phenotypes displayed by 4week-old soil-grown wt (SSI2; Col-0 ecotype), ssi2, ssi2 sid2, ssi2 pad4, ssi2eds5, ssi2 pad4 sid2 and ssi2 eds5 sid2 plants (scale, $0.5 \mathrm{~cm}$ ). (B) Microscopy of trypan blue-stained leaves shown in (A) (scale bars, 270 microns). (C) Expression of $P R-1$ gene in indicated genotypes. Total RNA was extracted from 4-week-old plants and used for RNA gel-blot analysis. Ethidium bromide staining of rRNA was used as the loading control. (D) RT-PGR analysis of $R$ genes in indicated genotypes. The level of $\beta$-tubulin was used as an internal control to normalize the amount of cDNA template. The SSI2 PAD4 SID2 and SSI2 EDS5 SID2 F2 plants showed wt-like morphology and showed wt-like expression of $P R-1$ and $R$ genes (data not shown). (E) Endogenous SA levels in the leaves of 4-

\section{References}

1. Flor H (1971) Current status of gene-for-gene concept. Annu Rev Phytopathol 9: 275-296.

2. Greenberg JT, Guo A, Klessig DF, Ausubel FM (1994) Programmed cell death in plants: a pathogen-triggered response activated coordinately with multiple defense functions. Cell 77: 551-563. week-old soil-grown plants. Values are presented as averages of four replicates and the error bars represent SD. (F) Endogenous SAG levels in the leaves of 4-week-old soil-grown plants. Error bars represent SD. The SSI2 PAD4 and SSI2 EDS5 plants showed wt-like morphology, accumulated wt-like levels of SA and showed wt-like expression of $P R-1$ and $R$ genes (data not shown). Statistical significances in $\mathrm{E}$ and $\mathrm{F}$ were determined using Student's $t$-test. Asterisks indicate data statistically significant compared to results from SSI2 (Col-0) plants $(\mathrm{P}<0.05, \mathrm{n}=4)$.

Found at: doi:10.1371/journal.pgen.1000545.s005 (1.09 MB TIF)

Table S1 A list of genetic crosses analyzed in this study. Found at: doi:10.1371/journal.pgen.1000545.s006 (0.08 MB DOG)

Table S2 Fold change in transcript levels of $R$ and $P R$ genes in ssi2 sid2 and ssi2 eds 1 sid 2 plants compared to results from Col-0 (wt) plants. $R$ genes showing $2-2.5,2.5-3$, and $>3$-fold activation are marked yellow, orange, or red, respectively. Transcriptional profiling was performed using Affymetrix arrays.

Found at: doi:10.1371/journal.pgen.1000545.s007 (0.09 MB DOC)

Table S3 FA composition from leaf tissues of SSI2 (Col-0), eds1, sid2, ssi2, ssi2 eds1, ssi2 sid2, and ssi2 eds1 sid2 plants. All measurements were made on 4 -week-old plants grown at $22^{\circ} \mathrm{C}$ and data are described as $\mathrm{mol} \% \pm \mathrm{SD}$ calculated for a sample size of six.

Found at: doi:10.1371/journal.pgen.1000545.s008 (0.06 MB DOC)

Table S4 FA composition from leaf tissues of SSI2 (Col-0), ssi2, ssi2 eds1, fad7, ssi2 fad7, ssi2 eds1 fad7, fad7 fad8, ssi2 fad7 fado and ssi2 eds 1 fad7 fado plants. All measurements were made on plants grown at $22^{\circ} \mathrm{C}$ and data are described as $\mathrm{mol} \% \pm \mathrm{SD}$ calculated for a sample size of six. nd, not detected.

Found at: doi:10.1371/journal.pgen.1000545.s009 (0.07 MB DOC)

Table S5 Primer sequences used to amplify various genes. Found at: doi:10.1371/journal.pgen.1000545.s010 (0.04 MB DOC)

\section{Acknowledgments}

We thank David Smith for critical comments; John Johnson for help with gas chromatography; Ludmila Lapchyk, Thomas Muse, and Lev Orlov for help with fatty acid extractions and genotyping; and Amy Crume for maintaining the growth facility. We thank Jeff Dangl for rps2-101c, RPM1$M Y C$, and RPS2-HA seeds; Keiko Yoshioka for Ler NahG; and Jane Parker for sag101 seeds. We thank Walter Grassmann for the Pseudomonas syringae strain containing AvrRPS4 and Barbara Kunkle for the AvrRPT2 strain. We thank Jack Morris for providing anti-TCV CP antisera.

\section{Author Contributions}

Conceived and designed the experiments: SGV RDJ MKM SZ ACGS AK PK. Performed the experiments: SCV RDJ MKM SZ ACGS YX DN AK PK. Analyzed the data: SCV RDJ MKM SZ ACCS YX MH AJS DN AK PK. Contributed reagents/materials/analysis tools: SCV RDJ MKM SZ ACCS YX MH AJS DN AK PK. Wrote the paper: AK PK.

3. Dangl JL, Dietrich RA, Richberg MH (1996) Death don't have no mercy: cell death programs in plant-microbe interactions. Plant Cell 8: 17931807.

4. Hammond-Kosack KE, Jones JDJ (1996) Resistance gene-dependent plant defense responses. Plant Cell 8: 1773-1791. 
5. Jabs T, Dietrich RA, Dangl JL (1996) Initiation of runaway cell death in an Arabidopsis mutant by extracellular superoxide. Science 273: 1853-1856.

6. Gray WM (2002) Plant defence: a new weapon in the arsenal. Curr Biol 12: R352-R354

7. Ward ER, Uknes SJ, Williams SC, Dincher SS, Wiederhold DL, et al. (1991) Coordinate gene activity in response to agents that induce systemic acquired resistance. Plant Cell 3: 1085-1094

8. Gaffney T, Friedrich L, Vernooij B, Negrotto D, Nye G, et al. (1993) Requirement of salicylic acid for the induction of systemic acquired resistance. Science 261: 754-756

9. Uknes S, Winter AM, Delaney T, Vernooij B, Morse A, et al. (1993) Biological induction of systemic acquired resistance in Arabidopsis. Mol Plant-Microbe Interact 6: 692-698.

10. Durrant WE, Dong X (2004) Systemic acquired resistance. Annu Rev Phytopathol 42: 185-209.

11. Kachroo A, Kachroo P (2006) Salicylic Acid-, Jasmonic Acid- and EthyleneMediated Regulation of Plant Defense Signaling. In Genetic Regulation of Plant Defense Mechanisms JaneSetlow, ed. Springer pubs 28: 55-83.

12. Kachroo P, Chandra-Shekara AC, Klessig D (2006) Plant signal transduction. and defense against viral pathogens. In: Advances in Viral Research Maramososch K, Shatkin AJ, eds. 66: 161-191.

13. Cao H, Glazebrook J, Clarke JD, Volko S, Dong X (1997) The Arabidopsis NPR 1 gene that controls systemic acquired resistance encodes a novel protein containing ankyrin repeats. Cell 88: 57-63.

14. Ryals JA, Weymann K, Lawton K, Friedrich L, Ellis D, et al. (1997) The Arabidopsis NIM1 protein shows homology to the mammalian transcription factor inhibitor $1 \kappa \mathrm{B}$. Plant Cell 9: 425-439.

15. Shah J, Tsui F, Klessig DF (1997) Characterization of a salicylic acid-insensitive mutant (sail) of Arabidopsis thaliana, identified in a selective screen utilizing the SA-inducible expression of the tms2 gene. Mol Plant-Microbe Interact 1: 69-78.

16. Falk A, Feys BJ, Frost LN, Jones JD, Daniels MJ, et al. (1999) EDS1, an essential component of $\mathrm{R}$ gene-mediated disease resistance in Arabidopsis has homology to eukaryotic lipases. Proc Natl Acad Sci USA 96: 3292-3297.

17. Nawrath C, Heck S, Parinthawong N, Metraux JP (2002) EDS5, an essential component of salicylic acid-dependent signaling for disease resistance in Arabidopsis, is a member of the MATE transport family. Plant Cell 1: 275-286.

18. Wildermuth MC, Dewdney J, Wu G, Ausubel FM (2001) Isochorismate synthase is required to synthesize salicylic acid for plant defense. Nature 414: 562-565.

19. Jirage D, Tootle TL, Reuber TL, Frost LN, Feys BJ, et al. (1999) Arabidopsis thaliana PAD4 encodes a lipase-like gene that is important for salicylic acid signaling. Proc Natl Acad Sci USA 96: 13583-13588.

20. Glazebrook J (2001) Genes controlling expression of defense responses in Arabidopsis -2001 status. Curr Opin Plant Biol 4: 301-308.

21. Aarts N, Metz M, Holub E, Staskawicz BJ, Daniels MJ, et al. (1998) Different requirements for EDS1 and NDR1 by disease resistance genes define at least two $\mathrm{R}$ gene-mediated signaling pathways in Arabidopsis. Proc Natl Acad Sci USA 95: 10306-10311.

22. Bittner-Eddy PD, Beynon JL (2001) The Arabidopsis downy mildew resistance gene, RPP13-Nd, functions independently of NDR1 and EDS1 and does not require the accumulation of salicylic acid. Mol Plant-Microbe Interact 14: 416-421.

23. Chandra-Shekara AC, Navarre D, Kachroo A, Kang H-G, Klessig DF, et al. (2004) Signaling requirements and role of salicylic acid in HRT- and rrtmediated resistance to turnip crinkle virus in Arabidopsis. Plant J 40: 647-659.

24. McDowell JM, Cuzick A, Can C, Beynon J, Dangl JL, et al. (2000) Downy mildew (Peronospora parasitica) resistance genes in Arabidopsis vary in functional requirements for NDR1, EDS1, NPR1 and salicylic acid accumulation. Plant J 6: 523-529.

25. Xiao S, Calis O, Patrick E, Zhang G, Charoenwattana P, et al. (2005) The atypical resistance gene, RPW8, recruits components of basal defence for powdery mildew resistance in Arabidopsis. Plant J 42: 95-110.

26. Feys BJ, Wiermer M, Bhat RA, Moisan LJ, Medina-Escobar N, et al. (2005) Arabidopsis SENESCENCE-ASSOCIATED GENE101 stabilizes and signals within an ENHANCED DISEASE SUSCEPTIBILITY1 complex in plant innate immunity. Plant Cell 9: 2601-2613.

27. Lipka V, Dittgen J, Bednarek P, Bhat R, Wiermer M, et al. (2005) Pre- and postinvasion defenses both contribute to nonhost resistance in Arabidopsis. Science 310: 1180-1183.

28. Vijayan P, Shockey J, Levesque CA, Cook RJ, Browse J (1998) A role for jasmonate in pathogen defence of Arabidopsis. Proc Natl Acad Sci USA 95: 7209-7214.

29. Kachroo P, Shanklin J, Shah J, Whittle EJ, Klessig DF (2001) A Fatty acid desaturase modulates the activation of defense signaling pathways in Plants. Proc Natl Acad Sci USA 98: 9448-9453.

30. Kachroo A, Lapchyk L, Fukushigae H, Hildebrand D, Klessig D, et al. (2003) Plastidial fatty acid signaling modulates salicylic acid- and jasmonic acidmediated defense pathways in the Arabidopsis ssi2 mutant. Plant Cell 15: 2952-2965.

31. Kachroo A, Venugopal SC, Lapchyk L, Falcone D, Hildebrand D, et al. (2004) Oleic acid levels regulated by glycerolipid metabolism modulate defense gene expression in Arabidopsis. Proc Natl Acad Sci USA 101: 5152-5157.

32. Weber H (2002) Fatty acid derived signals in plants. Curr Opin Plant Biology 7: 217-224.
33. Li C, Liu G, Xu C, Lee GI, Bauer P, et al. (2003) The Tomato Suppressor of prosystemin-mediated responses2 Gene Encodes a Fatty Acid Desaturase Required for the Biosynthesis of Jasmonic Acid and the Production of a Systemic Wound Signal for Defense Gene Expression. Plant Cell 15: 1646-1661.

34. Yaeno T, Matsuda O, Iba K (2004) Role of chloroplast trienoic fatty acids in plant disease defense responses. Plant J 40: 931-941.

35. Xia Y, Gao Q-M, Yu K, Navarre D, Hildebrand D, et al. (2009) An intact cuticle in distal tissues is essential for the induction of systemic acquired resistance in plants. Cell Host \& Microbe 5: 151-165.

36. Shah J, Kachroo P, Nandi A, Klessig DF (2001) A loss-of-function mutation in the Arabidopsis SSI2 gene confers SA- and NPR1-independent expression of PR genes and resistance against bacterial and oomycete pathogens. Plant $\mathrm{J}$ 25: $563-574$.

37. Chandra-Shekara AC, Venugopal SC, Barman SR, Kachroo A, Kachroo P (2007) Plastidial fatty acid levels regulate resistance gene-dependent defense signaling in Arabidopsis. Proc Natl Acad Sci USA 104: 7277-7282.

38. Kachroo P, Kachroo A, Lapchyk L, Hildebrand D, Klessig D (2003a) Restoration of defective cross talk in ssi2 mutants; Role of salicylic acid, jasmonic acid and fatty acids in SSI2-mediated signaling. Mol Plant-Microbe Interact 11: 1022-1029.

39. Kachroo A, Shanklin J, Lapchyk L, Whittle E, Hildebrand D, et al. (2007) The Arabidopsis stearoyl-acyl carrier protein-desaturase family and the contribution of leaf isoforms to oleic acid synthesis. Plant Mol Biol 63: 257-271.

40. Kachroo P, Venugopal SC, Navarre DA, Lapchyk L, Kachroo A (2005) Role of salicylic acid and fatty acid desaturation pathways in ssi2-mediated signaling. Plant Physiol 139: 1717-1735.

41. Kachroo A, Daqi F, Havens W, Navarre R, Kachroo P, et al. (2008) Virusinduced gene silencing of stearoyl-acyl carrier protein-desaturase in soybean results in constitutive defense and enhanced resistance to pathogens. Mol PlantMicrobe Interact 21: 564-575.

42. Jiang CJ, Shimono M, Maeda S, Inoue H, Mori M, et al. (2009) Suppression of the rice fatty-acid desaturase gene OsSSI2 enhances resistance to blast and leaf blight diseases in rice. Mol Plant-Microbe Interact, In press.

43. Nawrath C, Métraux JP (1999) Salicylic acid induction-deficient mutants of Arabidopsis express $P R-2$ and $P R-5$ and accumulate high levels of camalexin after pathogen inoculation. Plant Cell 11: 1393-1404.

44. Chen Z, Kloek AP, Boch J, Katagiri F, Kunkel BN (2000) The Pseudomonas syringae avrRpt2 gene product promotes pathogen virulence from inside plant cells. Mol Plant-Microbe Interact 13: 1312-1321.

45. Wiermer M, Feys BJ, Parker JE (2005) Plant immunity: the EDS1 regulatory node. Curr Opin Plant Biol 8: 383-389.

46. Bartsch M, Gobbato E, Bednarek P, Debey S, Schultze JL, et al. (2006) Salicylic acid-independent ENHANCED DISEASE SUSCEPTIBILITY1 signaling in Arabidopsis is regulated by the monooxygenase FMO1 and the nudix hydrolase NUDT7. Plant Cell 18: 1038-1051.

47. Xing D, Chen Z (2006) Effects of mutations and constitutive overexpression of EDS1 and PAD4 on plant resistance to different types of microbial pathogens. Plant Sci 171: 251-262.

48. Yang S, Hua J (2004) A haplotype-specific resistance gene regulated by BONZAI1 mediates temperature-dependent growth control in Arabidopsis. Plant Cell 16: 1060-1071.

49. Leeuwen HV, Kliebenstein DJ, West MAL, Kim K, Poecke RV, et al. (2007) Natural variation among Arabidopsis thaliana accessions for transcriptome response to salicylic acid. Plant Cell 19: 2099-2110.

50. Bouchabke O, Chang F, Simon M, Voisin R, Pelletier G, et al. (2008) Natural variation in Arabidopsis thaliana as a tool for highlighting differential drought responses. PLoS ONE 3(2): e1705. doi:10.1371/journal.pone.0001705.

51. Sandra SL, Amasino RM (1996) Ecotype-specific expression of a flowering mutant phenotype in Arabidopsis thaliana. Plant Physiol 111: 641-644.

52. Stokes TL, Kunkel BN, Richards EJ (2002) Epigenetic variation in Arabidopsis disease resistance. Genes Dev 16: 171-182.

53. Rodriguez-Rodriguez RA, Tabernero A, Velasco A, Lavado EM, Medina JM (2004) The neurotrphic effect of oleic acid includes dendritic differentiation and the expression of the neuronal basic helix-loop-helix transcription factor. J Neurochem 88: 1041-1051.

54. Stremmel W, Strohmeyer G, Borchard F, Kochwa S, Berk PD (1985) Isolation and partial characterization of a fatty acid binding protein in rat liver plasma membrane. Proc Natl Acad Sci USA 82: 4-8.

55. Svanborg C, Agerstam H, Aronson A, Bjerkvig R, Düringer C, et al. (2003) HAMLET kills tumor cells by an apoptosis-like mechanism-cellular, molecular, and therapeutic aspects. Adv Cancer Res 88: 1-29.

56. Menendez JA, Lupu R (2006) Oncogenic properties of the endogenous fatty acid metabolism: molecular pathology of fatty acid synthase in cancer cells. Curr Opin Clin Nutr Metab Care 9: 346-357.

57. Wang C, Wang X (2001) A novel phospholipase D of Arabidopsis that is activated by oleic acid and associated with the plasma membrane. Plant Physiol 127: 1102-1112

58. Fox SR, Hill LM, Rawsthorne S, Hills MJ (2000) Inhibition of the glucose-6phosphate transporter in oilseed rape (Brassica napus L.) plastids by acyl-CoA thioesters reduces fatty acid synthesis. Biochem J 352: 525-532.

59. Dempsey DA, Wobbe KK, Klessig DF (1993) Resistance and susceptible responses of Arabidopsis thaliana to turnip crinkle virus. Phytopathology 83: $1021-1029$ 
60. Oh J-W, Kong W, Song C, Carpenter CD, Simon AE (1995) Open reading frames of turnip crinkle virus involved in satellite symptom expression and incompatibility with Arabidopsis thaliana ecotype Dijon. Mol Plant-Microbe Interact 8: 979-987.
61. Dahmer ML, Fleming PD, Collins GB, Hildebrand DF (1989) A Rapid screening for determining the lipid composition of soybean seeds. J Am Oil Chem 66: 534-538.

62. Ghabrial SA, Schultz FG (1983) Serological detection of bean pod mottle virus in bean leaf beetles. Phytopathology 73: 480-483. 